Article

\title{
Annual Gross Primary Production from Vegetation Indices: A Theoretically Sound Approach
}

\author{
María Amparo Gilabert *, Sergio Sánchez-Ruiz and Álvaro Moreno \\ Environmental Remote Sensing Group (UV-ERS), Departament Física de la Terra i Termodinàmica, \\ Facultat de Física, Universitat de València, Dr. Moliner 50, 46100 Burjassot, Spain; \\ sergio.sanchez@uv.es (S.S.-R.); alvaro.moreno@uv.es (Á.M.) \\ * Correspondence: m.amparo.gilabert@uv.es; Tel.: +34-963-543-118
}

Academic Editors: Lenio Soares Galvao and Prasad S. Thenkabail

Received: 29 November 2016; Accepted: 16 February 2017; Published: 23 February 2017

\begin{abstract}
A linear relationship between the annual gross primary production (GPP) and a PAR-weighted vegetation index is theoretically derived from the Monteith equation. A semi-empirical model is then proposed to estimate the annual GPP from commonly available vegetation indices images and a representative PAR, which does not require actual meteorological data. A cross validation procedure is used to calibrate and validate the model predictions against reference data. As the calibration/validation process depends on the reference GPP product, the higher the quality of the reference GPP, the better the performance of the semi-empirical model. The annual GPP has been estimated at 1-km scale from MODIS NDVI and EVI images for eight years. Two reference data sets have been used: an optimized GPP product for the study area previously obtained and the MOD17A3 product. Different statistics show a good agreement between the estimates and the reference GPP data, with correlation coefficient around 0.9 and relative RMSE around $20 \%$. The annual GPP is overestimated in semiarid areas and slightly underestimated in dense forest areas. With the above limitations, the model provides an excellent compromise between simplicity and accuracy for the calculation of long time series of annual GPP.
\end{abstract}

Keywords: annual GPP; MODIS; NDVI; EVI; PAR; Monteith model

\section{Introduction}

The analysis of changes in the long-term estimates of the $\mathrm{CO}_{2}$ ecosystem-atmosphere fluxes is important to establish the global carbon balance, especially in forest ecosystems, the main sinks of atmospheric carbon in the biosphere. A key factor of this balance is the gross primary production (GPP), which represents the total carbon uptake through photosynthesis per unit of time and per unit of area. Although GPP is the source of carbon for all carbon fluxes in the ecosystem, there is no direct method of measurement. GPP is calculated from in situ net primary production data acquired in eddy covariance (EC) towers after correction for respiration losses [1,2]. Ecosystem models [3] validated against EC data and combined with meteorological and remotely sensed data $[4,5]$ allow for the estimation of GPP across space and time and, hence, for the quantification of carbon fluxes at regional to global scales [2].

The GPP is the rate at which vegetation converts light into chemical energy by photosynthesis. As the photosynthesis is driven by solar radiation, GPP can be estimated using the Monteith equation [6].

$$
\mathrm{GPP}=\varepsilon f_{\mathrm{APAR}} \mathrm{PAR}
$$


where PAR is the flux density of photosynthetically-active radiation, i.e., the global incident radiation in the range $400-700 \mathrm{~nm} ; f_{\text {APAR }}$ is a structural variable that represents the fraction (between 0 and 1 ) of incident PAR absorbed by the canopy; and $\varepsilon\left(\mathrm{g} \cdot \mathrm{MJ}^{-1}\right)$ is the conversion efficiency (also known as light-use efficiency (LUE)). When the quantities in Equation (1) are defined on a daily basis, a subscript $i$ ranging from 1 to 365 is added to them. The units of $\mathrm{GPP}_{i}$ and $\mathrm{PAR}_{i}$ are $\mathrm{g} \cdot \mathrm{m}^{-2} \cdot \mathrm{day}^{-1}$ and MJ.day ${ }^{-1}$, respectively.

The annual GPP for the year $Y$, in $\mathrm{kg} \cdot \mathrm{m}^{-2} \cdot \mathrm{yr}^{-1}$, is the sum of the corresponding daily values:

$$
\mathrm{GPP}_{\text {annual }}^{Y}=\sum_{i} \mathrm{GPP}_{i}^{Y}=\sum_{i} \varepsilon_{i}^{Y} f_{\mathrm{APAR}, i}^{Y} \operatorname{PAR}_{i}^{Y}
$$

Taking into account the loss due to autotrophic respiration, the GPP annual can be used to assess the carbon sequestration into dry matter during a year (annual net primary production), and hence to quantify the changes in biomass over long periods of time. However, obtaining long time series of $\mathrm{GPP}_{\text {annual }}$ from daily GPP values is a time-consuming process that requires a huge number of inputs that might be unavailable, especially in retrospective studies [4].

In this work, a semi-empirical model that avoids the calculation of all the factors in Equation (1) is proposed to estimate the annual GPP. As the next section will show, our approach relies on vegetation indices (VIs) products commonly available such as the Normalized Difference Vegetation Index (NDVI) [7] and the Enhanced Vegetation Index (EVI) [8]. In this case, the two MODIS standard VI products have been used. On the one hand, MODIS NDVI is included since it is referred as the "continuity index" [8] to the existing 30+ year NOAA-AVHRR derived NDVI time series, which can be extended to provide a longer-term data record required in climatic studies. On the other hand, EVI has been shown to improve NDVI sensitivity in dense vegetation regions and a better performance to minimize soil and atmosphere influences [8].

\section{A Theoretically Sound Approach}

The incident irradiance at the surface depends on the extraterrestrial irradiance and on the atmospheric conditions. The brightness variation of the Sun due to the sunspot cycle (with a period of ca. 11 years) provokes changes in the extraterrestrial global irradiance smaller than 0.1\% [9]. Hence, the extraterrestrial irradiance is practically constant. However, the surface global irradiance at a given location might be highly variable since it is affected by random changes due to atmospheric conditions, which introduce an inter-annual variation. Regarding the long-term trends in the global irradiance at the surface, a general decrease ("global dimming") has been reported during the last half century both in the northern and southern hemisphere, which might be related to a decrease of atmospheric transmittance due to changes in cloud characteristics and in atmospheric aerosols [10,11]. Nevertheless, in the last three decades, these changes have been less significant or even ceased [12].

According to the above considerations, the inter-annual variations of the annual PAR should be negligible. Although $\operatorname{PAR}_{i}^{Y}$ in Equation (2) might show random inter-annual variations associated to atmospheric state, it can be approximated (at each location) by a typical or representative value PAR ${ }_{i}^{\circ}$ that shows the main seasonal periodicity (associated exclusively to geometric factors). This assumption means that the effect of the changes of solar irradiance on annual GPP is less important than that due to vegetation changes (as discussed in Section 4). Radiation explains most of the variation in canopy photosynthesis over short periods, but environmental factors such as water availability become more important over long periods [12-15]. Since alterations in global solar irradiance only have a small impact on $\mathrm{GPP}_{\text {annual }}$, the observed inter-annual variability in GPP annual has to be related to structural

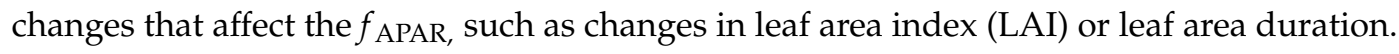


The $f_{\text {APAR }}$ is related to the vegetation structure and pigment content. It is frequently obtained from remote sensing data using vegetation indices (VIs) [16-20]. Some authors use the VIs as proxies of both $\varepsilon$ and $f_{\mathrm{APAR}}$ and rewrite Equation (1) as GPP $=\mathrm{VI} \times \mathrm{VI} \times \mathrm{PAR}[21,22]$. In the latter case, both broad-band VIs and narrow-band indices can be considered. The Photochemical Reflectance Index (PRI) is a narrow-band VI [23] that is potentially connected with $\varepsilon$ [24]. The GPP has also been directly related to PAR through the chlorophyll content, which is in turn closely related to green $f_{\text {APAR }}[25,26]$. In any case, a linear relation with a vegetation index, such as the NDVI and the EVI, is a realistic approximation for the evaluation of $f_{\text {APAR }}$. This has been sufficiently shown by several authors, as mentioned above, and does not require further analysis.

As commented by some authors [27], whereas $f_{\mathrm{APAR}, i}$ is related to the vegetation structure and pigment pools, the conversion efficiency is related to the physiology. The daily conversion efficiency $\varepsilon_{i}$ can vary spatially between biomes, ecosystems, and plant species, and temporally during the growing season due to environmental and physiological limitations [28-32]. The daily conversion efficiency is generally taken as the product of a biome-specific maximum value $\left(\mathrm{g} \cdot \mathrm{MJ}^{-1}\right)$ and several dimensionless factors accounting for the efficiency reduction due to different types of stress, such as the thermal and the water stress. Our study area is characterized by different Mediterranean ecosystems where the water stress introduces most of the inter-annual variability in $\varepsilon_{i}[4,13]$. On a daily scale, the different types of stress must be accounted for at quasi-real time, which is rather difficult and frequently requires actual meteorological data. Nevertheless, it has been shown that after relatively long stress periods, the plant photosynthetic apparatus is damaged and ultimately leads to structural canopy alteration (i.e., a decrease in green LAI and therefore in $f_{\text {APAR }}$ ). This alteration can be noticed, with a time delay of one or two months [33,34], in broad-band spectral indices such as the NDVI and narrow-band indices such as the PRI. In particular, numerous studies carried out in different environments have shown that NDVI is sensitive to vegetation water stress [35,36].

It can be safely assumed that the effects of the different down-regulating factors at annual scale affect the $f_{\text {APAR, }}$, since stresses acting on the canopy finally produce either less chlorophyll and/or less foliage and reduce the VI value. Hence, at annual scale, the conversion efficiency $\varepsilon$ can be considered to be independent of time, and approximated by the ecosystem maximum efficiency. As $f_{\mathrm{APAR}, i}$ and $\varepsilon_{i}$ can be confounded to varying degrees depending on the underlying dynamic biological processes and on their exact definition [27], with this approach we are avoiding a further insight in these concepts and in their exact operational definition. In fact, this approach takes into account the coordinate response or functional convergence [27] of both variables in the presence of nutrient or water constraints that limit plant growth as well as plant structure and pigment content.

Table 1 summarizes the hypotheses concerning the estimation of $\mathrm{GPP}_{\text {annual }}^{Y}(\mathrm{H} 1$ is analyzed in next section). Hence, the variations from one year $Y$ to another are attributed to those of $f_{\text {APAR, }}$ i.e., to VI. From Equation (2) and the hypotheses in Table 1, an approximated GPP ${ }_{\text {annual }}^{Y}$ can thus be calculated as

$$
\begin{gathered}
\mathrm{GPP}_{\text {annual }}^{Y}=\varepsilon_{\max } \sum_{i}\left[\left(a+b \mathrm{VI}_{i}^{Y}\right) \mathrm{PAR}_{i}^{\circ}\right] \\
\mathrm{GPP}_{\text {annual }}^{Y}=C_{1}+C_{2} \overline{\mathrm{VI}}^{Y} \\
C_{1}=\varepsilon_{\max } a \sum_{i} \mathrm{PAR}_{i}^{\circ}
\end{gathered}
$$

where

$$
C_{2}=\varepsilon_{\max } b \sum_{i} \operatorname{PAR}_{i}^{\circ}
$$

That is, $C_{1}$ and $C_{2}$ are constant for a specific vegetation type, and 


$$
\overline{\mathrm{VI}}^{Y}=\frac{\sum_{i} \mathrm{VI}_{i}^{Y} \mathrm{PAR}_{i}^{\circ}}{\sum_{i} \mathrm{PAR}_{i}^{\circ}}
$$

This average VI is physically sound as it is an average over the energy received per surface area. Equations (3)-(7) require the series $\mathrm{VI}_{i}^{Y}$ and $\operatorname{PAR}_{i}^{\circ}$ (which is the same for all years), and the parameters, $a, b$ and $\varepsilon_{\max }$.

In this work, the annual GPP is obtained at 1-km spatial resolution from the MODIS VI standard products (NDVI and EVI) using the semi-empirical model in Equation (4). After a brief analysis of H1, the coefficients $C_{1}$ and $C_{2}$ are obtained and discussed as a function of the vegetation type. For the sake of clarity, GPP annual refers to annual GPP values obtained using Equation (2) since they are considered our "reference values", whereas GPP annual refers to estimated values using the semi-empirical model. Data from 2005 to 2012 are employed in the study. The performance of the model is assessed in its ability to reproduce annual GPP inter-annual variations in close agreement with those shown by the reference data.

Table 1. Hypotheses underlying the estimation of annual GPP by means of the semi-empirical model.

\begin{tabular}{cll}
\hline Hypothesis & & \multicolumn{1}{c}{ Description } \\
\hline $\mathrm{H} 1$ & $\mathrm{PAR}_{i}^{Y}=\mathrm{PAR}_{i}^{\circ}$ & $\begin{array}{l}\text { PAR inter-annual variations effects on annual GPP are } \\
\text { negligible. A typical or representative PAR series, } \mathrm{PAR}_{i}^{\circ}, \\
\text { can be used to characterize its seasonal pattern, } \\
\text { independently of the year. }\end{array}$ \\
\hline $\mathrm{H} 2$ & $f_{\mathrm{APAR}, i}^{Y}=a+b \mathrm{VI}_{i}^{Y}$ & $\begin{array}{l}\text { A linear relation with a VI (such as NDVI and EVI) is } \\
\text { a reasonable approximation for } f_{\mathrm{APAR}} \text { evaluation. }\end{array}$ \\
\hline $\mathrm{H} 3$ & $\varepsilon_{i}^{Y}=\varepsilon_{\max }$ & $\begin{array}{l}\text { The conversion efficiency is independent of time and } \\
\text { approximated by the ecosystem maximum efficiency at } \\
\text { annual scale. }\end{array}$ \\
\hline
\end{tabular}

\section{Materials and Methods}

\subsection{Study Area}

Spain has remarkable landscape diversity and a wide range of ecosystems due to its geographic position in southwestern Europe, climate, geological features and relief, with elevation varying from sea level to $3479 \mathrm{~m}$. A vast plateau surrounded by a number of mountain ranges dominates the central part of Spain. Synoptic air masses create a NW to SE gradient of water availability (total annual precipitation varies from $2000 \mathrm{~mm}$ to $120 \mathrm{~mm}$ ), ranging from Atlantic humid climate zones on the north coast to Mediterranean climate on the east coast, the SE corner becoming the most arid zone of Europe [37]. Spain has a mosaic of land cover that includes significant areas of traditional and newly developed agriculture ( $49 \%$ of land), dominated by non-irrigated land. These areas are embedded in a matrix of natural and semi-natural vegetation ( $47 \%$ of land), mainly occupied by shrublands, and broadleaved or coniferous forests [38]. Vegetation distribution is strongly controlled by aridity, and drought conditions have a marked influence on vegetation cover and activity. The droughts that affect the semiarid areas represent an important factor in environmental degradation.

Figure 1 shows a precipitation map obtained averaging the annual precipitation of the eight years analyzed in this study (2005-2012), an average annual PAR image and the reference annual GPP for 2011 (both products will be described later). 


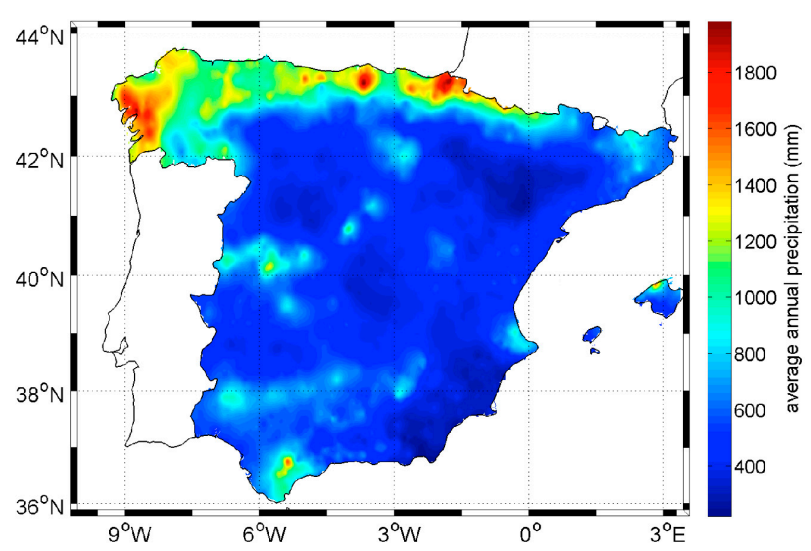

(a)

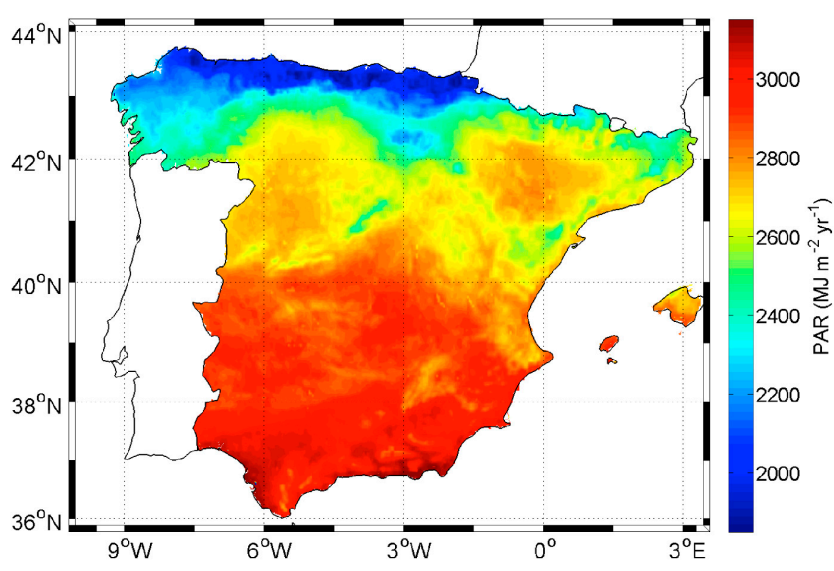

(b)

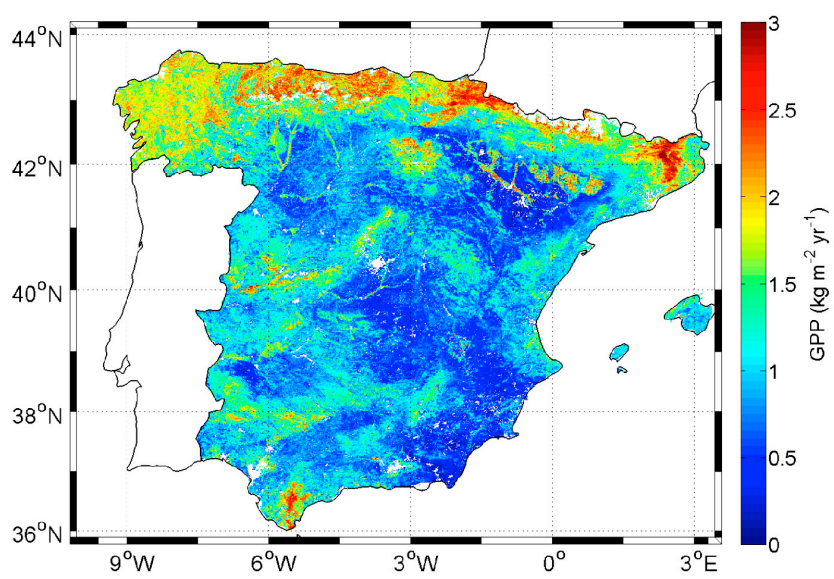

(c)

Figure 1. Average annual precipitation (a); and average annual PAR (b) for the study area using the eight years analyzed in the study (2005-2012); and (c) annual reference GPP for 2011.

\subsection{Images}

\subsubsection{Daily PAR Images}

Daily PAR images were obtained from daily irradiation images over Spain. The latter were calculated using two different procedures, previously inter-compared to ensure their homogeneity. Only the first procedure uses a satellite product, the down-welling surface short-wave radiation 
flux (DSSF) from SEVIRI/MSG images [39]. Therefore, it is preferred from an operational point of view. In this procedure, the DSSF product was integrated along a day to obtain the daily irradiation. The DSSF data are, in the native geostationary projection, centered at $0^{\circ}$ longitude and with a sampling distance of $3 \mathrm{~km}$ at the sub-satellite point. DSSF data were downscaled using the spatial disaggregation of the irradiance with a digital elevation model, DEM [40]. First, these data were re-projected and spatially smoothed by means of a linear interpolation to obtain 1-km lat/lon global irradiance images. This procedure removed the sharp borders or discontinuities between adjacent pixels. When no surrounding data were available (e.g., in the coastline), a fast technique to interpolate the images was developed. A further topographic correction was applied, which included the elevation correction and slope and aspect effects by means of a DEM. This procedure was used from 2007 to 2012. The resulting PAR images at 1-km spatial resolution present a mean absolute error (MAE) ranging from $0.5 \mathrm{MJ} \cdot \mathrm{m}^{-2} \cdot \mathrm{day}^{-1}$ to $0.9 \mathrm{MJ} \cdot \mathrm{m}^{-2} \cdot \mathrm{day}^{-1}$ in rugged terrain. Although the DSSF product is preferred from an operational point of view, a second procedure was employed when DSSF images were not available. This second procedure [41] applies artificial neural networks to temperature and precipitation maps generated by ordinary kriging from in situ data. Unlike temperature and precipitation, solar radiation data are recorded only at a limited number of weather stations in Spain and thus solar radiation maps cannot be obtained directly interpolating those data. However, they can be estimated using extraterrestrial irradiation and air temperature and precipitation, which serve to characterize atmospheric transmittance. The MAE for PAR was also rather low in this case, about $1.2 \mathrm{MJ} \cdot \mathrm{m}^{-2} \cdot \mathrm{day}^{-1}$. A relationship between both series was found and used to fill the gaps in the first series.

According to climate records (www.aemet.es), the study period (2005-2012) presents remarkable weather heterogeneity. It comprises hot and dry years as well as hot and humid ones. However, these general features depend on each particular region, and the drought events are non-uniform and affect different regions on different years.

\subsubsection{Daily GPP Images}

Daily GPP images at 1-km resolution were obtained for the period 2005-2012 following a procedure based on the optimization of Monteith's approach, Equation (1), by adjusting the inputs $\left(f_{\text {APAR }}\right.$, PAR and $\left.\varepsilon\right)$ for the study area. This optimized GPP product is driven by meteorological and satellite data (MODIS/TERRA and SEVIRI/MSG). Daily PAR was obtained as described above. $f_{\text {APAR }}$ was calculated by applying to MODIS data (at 1-km spatial resolution and 8-day temporal resolution) the algorithm that is actually used to derive the SEVIRI/MSG $f_{\text {APAR }}$ product, delivered by the LSA SAF network (EUMETSAT) (http:/ / landsaf.meteo.pt) at 3.1-km spatial resolution (sub-satellite point) and daily frequency over the geostationary MSG grid. This algorithm uses the Renormalized Difference Vegetation Index, RDVI [42]. Subsequently, the $f_{\text {APAR }}$ series were filtered and interpolated using an adapted (iteratively reweighted) local regression filter (LOESS) [43]. This procedure takes into account the data quality flags and has shown a very good performance; it is particularly resistant to outliers and offers an optimal reconstruction even in most extreme situations with long seasonal gaps. In order to assign a value of $\varepsilon_{\max }$ to the different cover types, a hybrid land-cover map for Spain [44] was used (see below). Meteorological data were used to characterize the $\varepsilon$ inter-annual variability due to water stress, which produces the most significant efficiency reduction in the study area. In particular, the water stress factor $C_{\mathrm{ws}}$ [5], which accounts for limited photosynthetic activity in case of short-term water stress, was obtained from a local water budget based on actual and potential evapotranspiration.

This daily GPP product was validated for 2008 and 2011 [4] by comparison with in situ GPP estimates from EC data (direct validation) and by inter-comparison with the MODIS GPP product (MOD17A3) [45], which will be also used in this work. The direct validation has evidenced an excellent agreement with correlations up to 0.98 in 2008 and 0.92 in 2011 in some sites. The inter-comparison has shown that the two GPP products are consistent temporally. However, a slightly decrease of the correlation has been observed in high precipitation areas (Northern Spain) and in semiarid areas 
(Southern Spain). Whereas the discrepancies on the northern region could be explained due to differences in the PAR (which seems to be better estimated in our approach), the discrepancies on the southern region could be related to the different way that the two GPP products account for the water stress. Our results evidence that the water stress factor $C_{\text {ws }}$ outperforms the VPD (vapor pressure deficit) used in the official MODIS product. A further analysis on the explanatory power of the optimized GPP in terms of its inputs showed, as expected, that PAR and $f_{\text {APAR }}$ are the most relevant inputs. Their relative importance depends on the location of the vegetation annual maximum so that the $f_{\text {APAR }}$ plays a major role on the GPP estimation when that maximum is not reached during solar solstice. Nevertheless, $\varepsilon$ has to be evaluated accurately in order to explain the GPP inter-annual variability associated with the water shortage typical of Mediterranean landscapes [4].

\subsubsection{Daily VI Images}

The MODIS standard VI product MOD13A2 [8] includes two gridded vegetation indices (NDVI and EVI) at 1-km spatial resolution and 16-day temporal resolution (https:/ / reverb.echo.nasa.gov/), and quality analysis (QA) with statistical data that indicate the quality of the VI product and input reflectance data. The VI products are corrected for molecular scattering, ozone absorption, and aerosols. The MODIS VI algorithm operates on a per-pixel basis and relies on multiple observations over a 16-day period to generate a composited VI.

The VI time series were filtered and interpolated using an adapted LOESS, the same procedure applied to $f_{\text {APAR }}$ series [43], to generate daily NDVI and EVI images.

\subsubsection{Vegetation Type Images}

Two vegetation classifications were used: (i) a hybrid land-cover map obtained by the synergistic combination of four land-cover classifications (CGL2000, CORINE, IGBP and GlobCover) that improves the performance of individual classifications by reconciling their best characteristics while avoiding their main weaknesses [44]; and (ii) an ecosystem functional type map that characterizes the patterns of diversity and status from functional attributes such as the NDVI, land surface temperature and albedo [38].

\subsection{Methodology}

Hypotheses 2 and 3 are supported by literature (see Section 1 ) and, therefore, they are accepted as a stating point of our methodology. Although $\mathrm{H} 1$ is also a sound hypothesis, its adequacy to our study area is assessed by statistical tests. They allow us to evaluate whether PAR inter-annual variations introduce negligible changes in annual GPP as compared to those due to the inter-annual variability of the VI.

As mentioned at the end of Section 2, once $\mathrm{H} 1$ is confirmed, $\mathrm{PAR}_{i}^{\circ}$ is calculated. This is considered as a typical or representative daily PAR series for each pixel of the study area. It is obtained by averaging the daily PAR for the eight-year dataset. The representative annual PAR is computed by summing the daily values, $\Sigma \mathrm{PAR}_{i}^{\circ}$. For each year $Y$ from 2005 to 2012, the average VI images $\left(\overline{\mathrm{NDVI}}^{Y}\right.$ and $\overline{\mathrm{EVI}}^{\mathrm{Y}}$ ) are obtained using Equation (7) and the GPP annual images are calculated using Equation (2) with the daily GPP images at 1-km spatial resolution described in Section 3.2.2.

Next, correlations between $\overline{\mathrm{NDVI}}^{Y}$ and $\mathrm{GPP}_{\text {annual }}^{\mathrm{REF}}$ images, and between $\overline{\mathrm{EVI}}^{Y}$ and $\mathrm{GPP}_{\text {annual }}^{\mathrm{REF}}$ images, are analyzed to establish two sets of coefficients $C_{1}$ and $C_{2}$. The calibration (obtaining $C_{1}$ and $C_{2}$ ) and testing of the semi-empirical model are performed simultaneously by means of a cross-validation procedure [46]. This procedure allowed us to calculate and test the model parameters from the eight years data used in this study. The cross-validation method systematically removes one case in a dataset (a year data in our case), derives a forecast from the remaining cases, and tests it on the removed case. The procedure is nonparametric and can be applied to any automated model-building technique. 
To carry out the cross-validation procedure, data are divided into eight partitions corresponding to each one of the eight available annual images of GPP and weighted NDVI. The procedure is as follows. For year $Y(=2005-2012)$, the images of years $\neq Y$ are used to train a linear model. The model is validated using the images of year $=Y$. The coefficient of correlation $(\mathrm{R}), \mathrm{MBE}$ (mean bias error), MAE (mean absolute error), RMSE (root mean square error), and their relative values (rMBE, rMAE, and rRMSE) are calculated. Finally, the mean and standard deviation of the regression coefficients are calculated and considered as the final regression coefficients of the model and their associated errors.

The cross validation is carried out in two ways: (i) considering a constant value of the conversion efficiency ( $C_{1}$ and $C_{2}$ are independent of the land-cover class); and (ii) considering that $C_{1}$ and $C_{2}$ depend on vegetation, according to the two thematic maps described in Section 3.2. A flowchart for $\mathrm{GPP}_{\text {annual }}$ estimation using the semi-empirical model is shown in Figure 2.

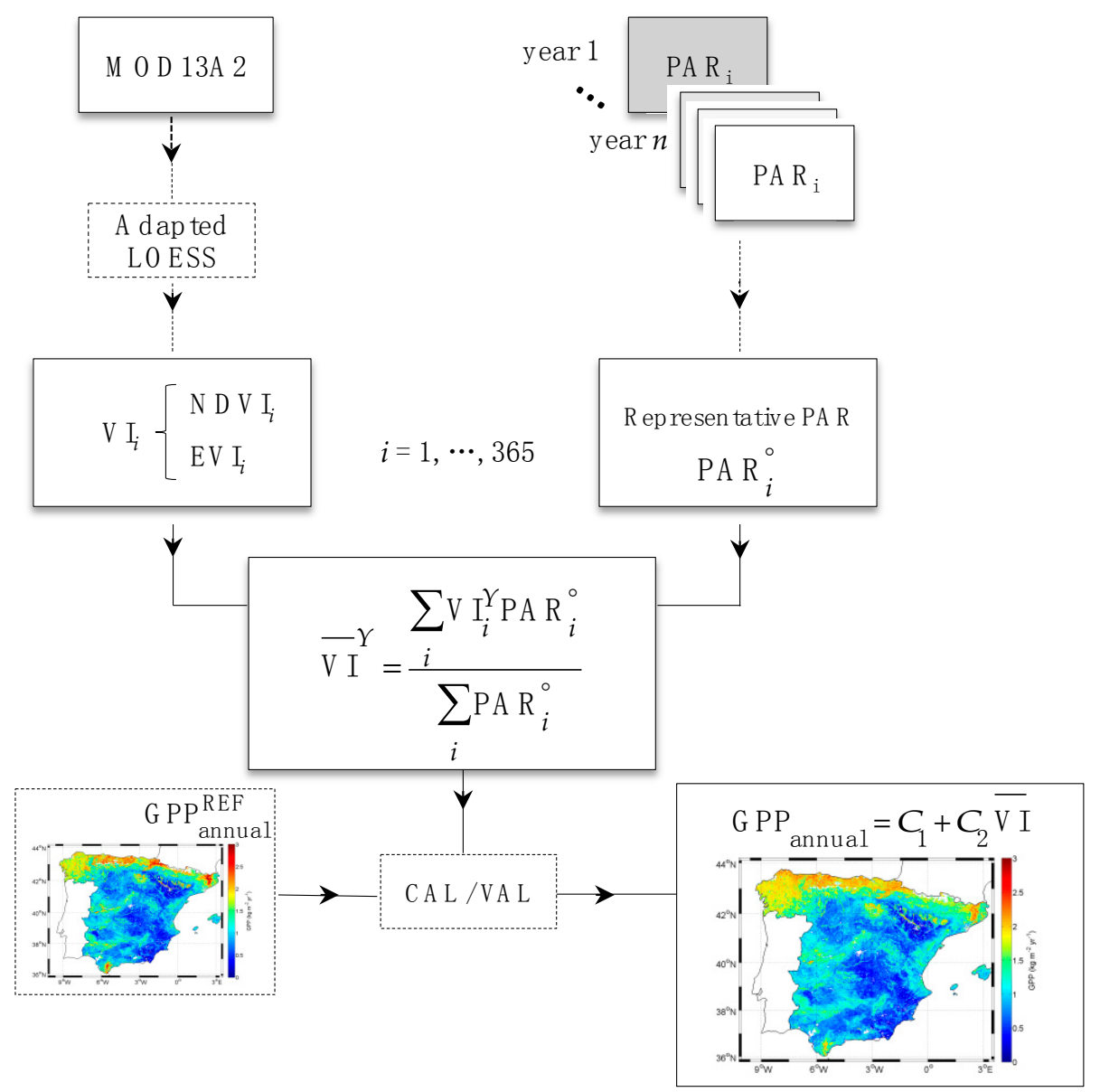

Figure 2. Flowchart of $\mathrm{GPP}_{\text {annual }}$ estimation using the PAR-weighted VI (being VI = NDVI, EVI).

\section{Results}

\subsection{H1 Hypothesis Testing}

Annual PAR images for the eight years (see Section 3.1) and a coefficient of variation image were calculated (Figure 3a). The coefficient of variation (mean value equal to 0.026) shows the inter-annual variability of the annual PAR throughout the period 2005-2012, which is less than 5\%, in the entire study area. Thus, the annual PAR can be considered practically constant. Its variation is ca. $50 \%$ lower than that corresponding to the annual mean NDVI and EVI (Figure 3b,c). Annual-mean VI and reference annual GPP series (not shown) present rather similar spatial patterns. A further analysis has 
been carried to assess the effects of both the daily PAR, NDVI and EVI inter-annual variability on the reference annual GPP.

The results of the correlations GPP/PAR (Figure 3d) show that only the $25 \%$ of the pixels present a $p$-value $\leq 0.05$, (i.e., statistically significant, with mean $R^{2}=0.62$ ), whereas $64 \%$ of the pixels show a $p$-value $\leq 0.05$ for the correlation GPP/NDVI $\left(R^{2}=0.73\right)$ and $65 \%$ for the GPP/EVI $\left(R^{2}=0.74\right)$. Therefore, the NDVI (and EVI) inter-annual variations play a significant role in the GPP inter-annual variations. As the daily PAR series of all eight years show similar characteristic seasonal patterns, hypothesis $\mathrm{H} 1$ is accepted. That is, we assume that annual PAR is practically constant (as compared with NDVI and EVI) and each pixel can be characterized by a representative $\operatorname{PAR}_{i}^{\circ}$ series. The annual representative PAR $\left(\Sigma \mathrm{PAR}_{i}^{\circ}\right)$ coincides with the average PAR shown in Figure $1 \mathrm{~b}$.

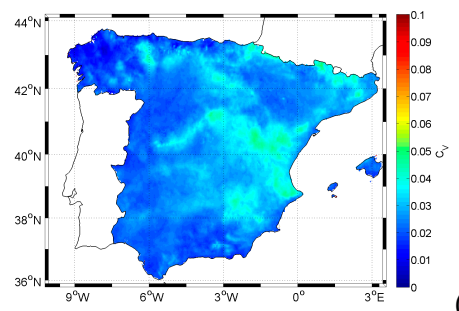

(a)

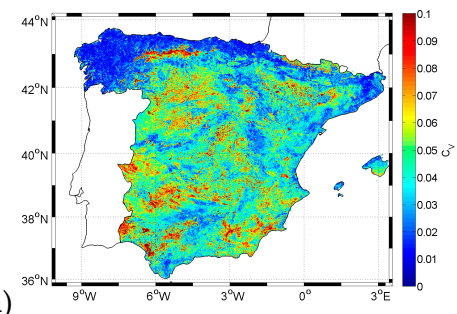

(b)

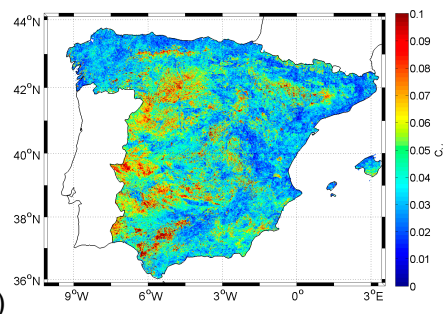

(c)

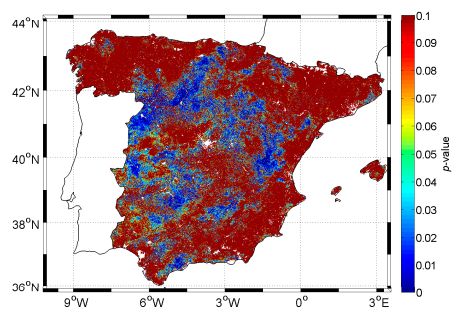

(d)

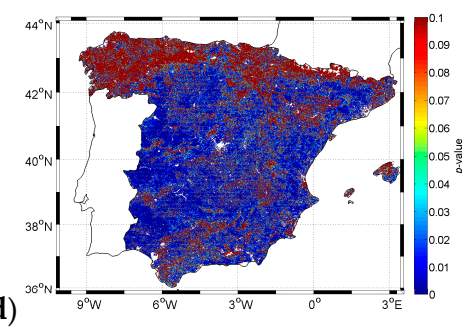

(e)

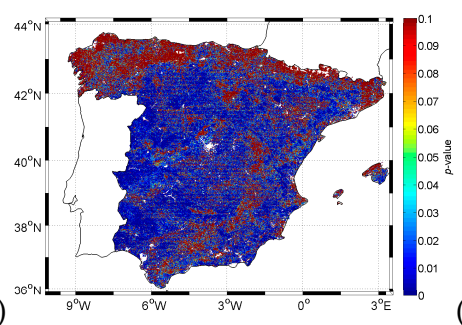

(f)
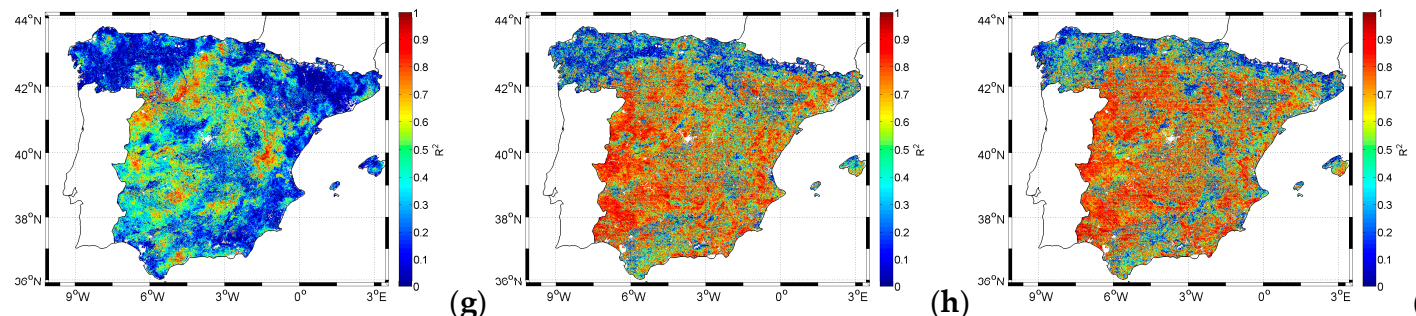

(i)

Figure 3. Coefficient of variation among the eight-year dataset of: (a) annual PAR; (b) annual mean NDVI; and (c) annual mean EVI. $p$-value of correlations between inter-annual variations for the eight years of annual GPP and those from: (d) annual PAR; (e) annual mean NDVI; and (f) annual mean EVI. $\mathrm{R}^{2}$ for the above correlations: (g) GPP/PAR; (h) GPP/NDVI; and (i) GPP/EVI.

\subsection{Calibration and Validation of the Semi-Empirical Model}

The density scatterplot of $\mathrm{GPP}_{\text {annual }}^{\mathrm{REF}}$ as a function of both $\overline{\mathrm{NDVI}}^{Y}$ and $\overline{\mathrm{EVI}}^{Y}$ for all the image pixels and all years (Figure 4a,b, respectively) evidences a practically linear correlation. Therefore, in a first step, the regression coefficients $C_{1}$ and $C_{2}$ (Equation (4), using reference annual GPP data) are obtained assuming a constant conversion efficiency value $\varepsilon$. The cross-validation procedure is applied to these data to obtain $C_{1}$ and $C_{2}$ using NDVI and EVI (Tables 2 and 3). The corresponding estimated GPP annual values using NDVI and EVI are shown in Figure 4c,d, respectively. Most of the estimates distribute along the 1:1 line, which indicates a good agreement between the reference and the estimated GPP. However, when using the NDVI, there is a cluster located at high levels of GPP that does not lie along the 1:1 line, which indicates an underestimation of the model for high GPP values. The corresponding 
pixels are located in dense forest areas (Figure 5). The last column in Table 3 shows the statistics of the correlation between estimated and reference annual GPP using the mean values of $C_{1}$ and $C_{2}$.

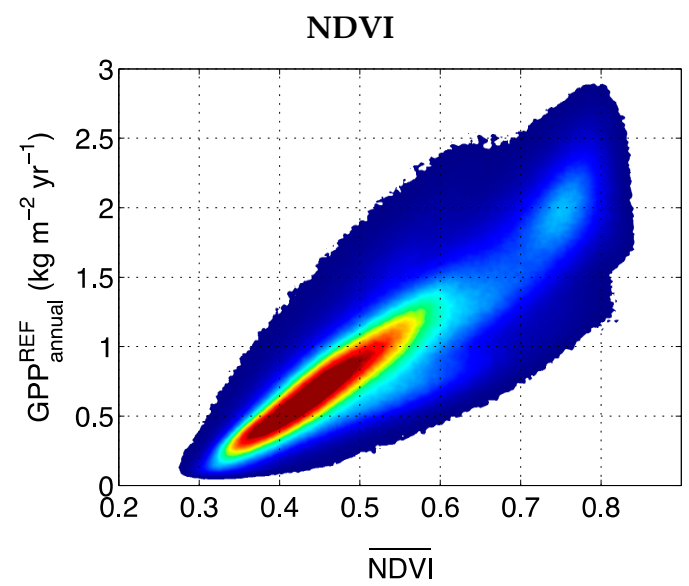

(a)

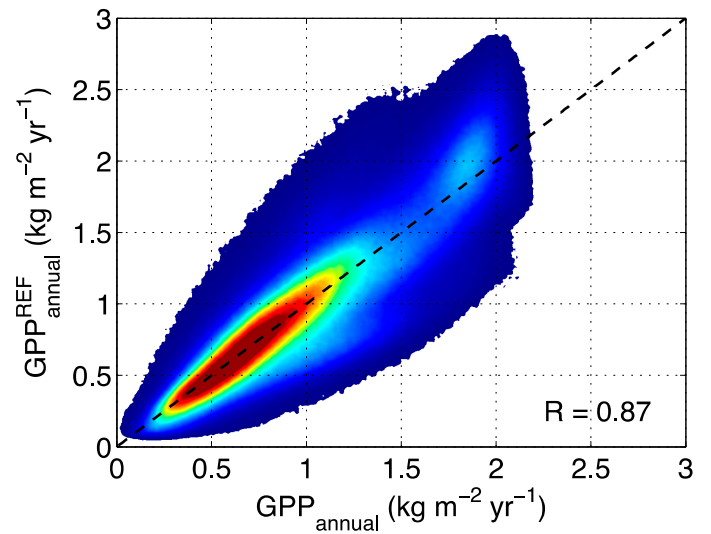

(c)

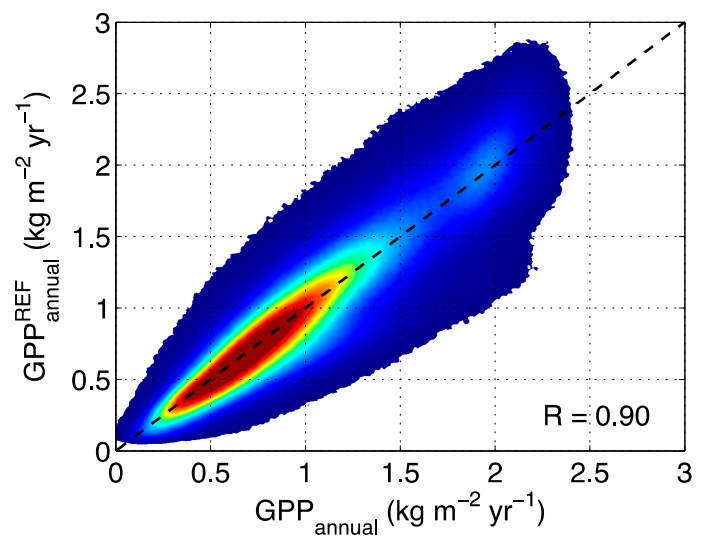

(e)

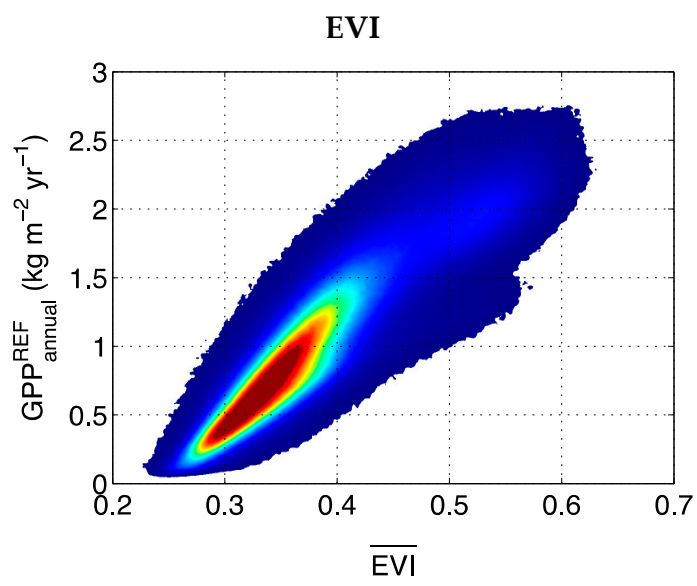

(b)

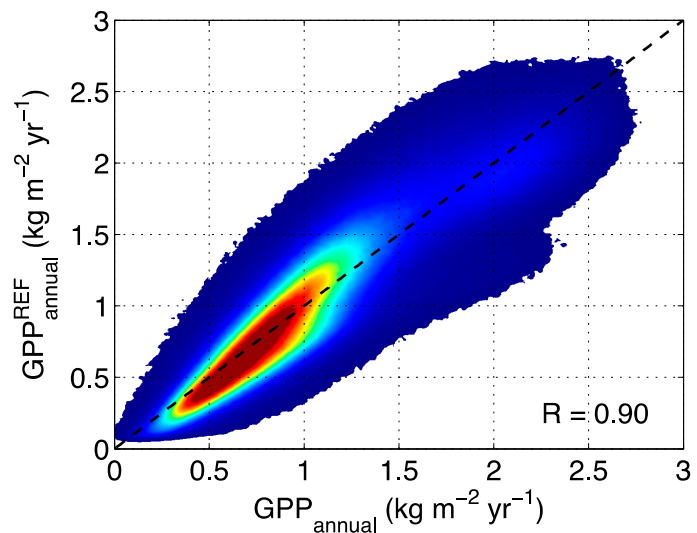

(d)

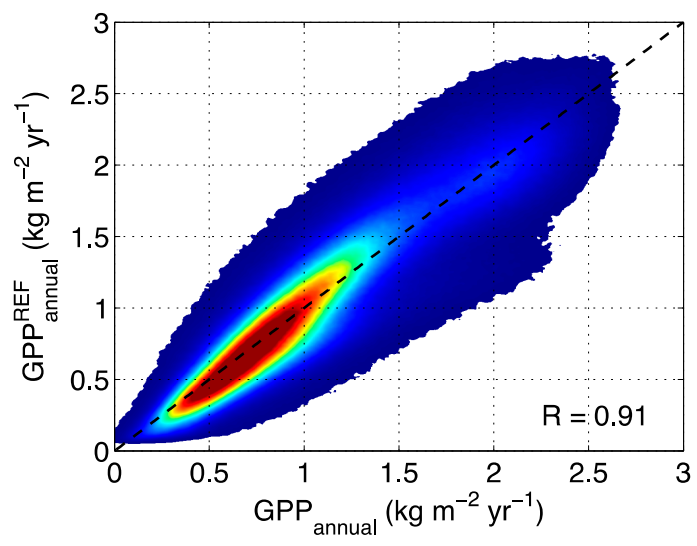

(f)

Figure 4. A density plot including all image pixels and all years evidences the correlation between: (a) GPP annual and $\overline{\mathrm{NDVI}}^{\mathrm{R}}$; and (b) GPP annual and $\overline{\mathrm{EVI}}^{\mathrm{R}}$. Correlation between $\mathrm{GPP}_{\text {annual }}^{\mathrm{REF}}$ and GPP annual estimated by the semi-empirical model with a constant conversion efficiency using: (c) NDVI; and (d) EVI. Correlation between $\mathrm{GPP}_{\text {annual }}^{\mathrm{REF}}$ and $\mathrm{GPP}_{\text {annual }}$ estimated by the semi-empirical model with a conversion efficiency depending on the land-cover type using: (e) NDVI; and (f) EVI (Reddish areas correspond to the highest point density. The dashed line is the 1:1 bisector). 
Table 2. Regression coefficients $C_{1}$ and $C_{2}\left(\mathrm{in} \mathrm{kg} \cdot \mathrm{m}^{-2} \cdot \mathrm{yr}^{-1}\right)$ for each iteration and their final values and errors. For each year, each coefficient has been obtained using the rest of the years. Results are shown for NDVI and EVI.

\begin{tabular}{|c|c|c|c|c|c|c|c|c|c|c|}
\hline \multicolumn{11}{|c|}{ NDVI } \\
\hline & 2005 & 2006 & 2007 & 2008 & 2009 & 2010 & 2011 & 2012 & Mean & Std \\
\hline$C_{1}$ & -1.031 & -1.050 & -1.030 & -1.027 & -1.021 & -1.029 & -1.038 & -1.022 & -1.031 & 0.009 \\
\hline$C_{2}$ & 3.843 & 3.862 & 3.819 & 3.818 & 3.818 & 3.826 & 3.848 & 3.828 & 3.833 & 0.017 \\
\hline \multicolumn{11}{|c|}{ EVI } \\
\hline & 2005 & 2006 & 2007 & 2008 & 2009 & 2010 & 2011 & 2012 & Mean & Std \\
\hline$C_{1}$ & -1.611 & -1.625 & -1.615 & -1.619 & -1.592 & -1.605 & -1.613 & -1.604 & -1.160 & 0.010 \\
\hline$C_{2}$ & 6.97 & 6.99 & 6.96 & 6.98 & 6.91 & 6.93 & 6.96 & 6.94 & 6.96 & 0.03 \\
\hline
\end{tabular}

Table 3. Validation statistics for each iteration and for the whole data set (in this case, using the mean values of $C_{1}$ and $C_{2}$ shown in Table 2). MBE, MAE and RMSE are expressed in $\mathrm{kg} \cdot \mathrm{m}^{-2} \cdot \mathrm{yr}^{-1}$. Results are shown for NDVI and EVI.

\begin{tabular}{|c|c|c|c|c|c|c|c|c|c|}
\hline \multicolumn{10}{|c|}{ NDVI } \\
\hline & 2005 & 2006 & 2007 & 2008 & 2009 & 2010 & 2011 & 2012 & All \\
\hline $\mathbf{R}$ & 0.88 & 0.85 & 0.86 & 0.87 & 0.88 & 0.86 & 0.86 & 0.88 & 0.87 \\
\hline MBE & 0.03 & -0.03 & -0.05 & -0.03 & 0.005 & -0.02 & 0.0008 & 0.04 & -0.008 \\
\hline MAE & 0.18 & 0.20 & 0.2 & 0.20 & 0.19 & 0.19 & 0.19 & 0.19 & 0.19 \\
\hline RMSE & 0.3 & 0.3 & 0.2 & 0.2 & 0.3 & 0.3 & 0.3 & 0.3 & 0.3 \\
\hline rMBE & 0.03 & -0.03 & -0.04 & -0.03 & 0.005 & -0.02 & 0.0008 & 0.04 & -0.006 \\
\hline rMAE & 0.20 & 0.19 & 0.18 & 0.18 & 0.20 & 0.18 & 0.18 & 0.19 & 0.19 \\
\hline rRMSE & 0.3 & 0.3 & 0.2 & 0.2 & 0.3 & 0.2 & 0.3 & 0.3 & 0.3 \\
\hline \multicolumn{10}{|c|}{ EVI } \\
\hline & 2005 & 2006 & 2007 & 2008 & 2009 & 2010 & 2011 & 2012 & All \\
\hline $\mathbf{R}$ & 0.91 & 0.89 & 0.90 & 0.90 & 0.91 & 0.89 & 0.89 & 0.90 & 0.90 \\
\hline MBE & 0.03 & -0.011 & -0.017 & -0.010 & -0.012 & -0.04 & -0.03 & 0.008 & -0.009 \\
\hline MAE & 0.16 & 0.17 & 0.17 & 0.17 & 0.17 & 0.17 & 0.18 & 0.17 & 0.17 \\
\hline RMSE & 0.2 & 0.2 & 0.2 & 0.2 & 0.2 & 0.2 & 0.2 & 0.2 & 0.2 \\
\hline rMBE & 0.04 & -0.011 & -0.015 & -0.009 & -0.013 & -0.03 & -0.03 & 0.008 & -0.008 \\
\hline rMAE & 0.18 & 0.17 & 0.15 & 0.16 & 0.17 & 0.16 & 0.17 & 0.18 & 0.17 \\
\hline rRMSE & 0.2 & 0.2 & 0.2 & 0.2 & 0.2 & 0.2 & 0.2 & 0.2 & 0.2 \\
\hline
\end{tabular}

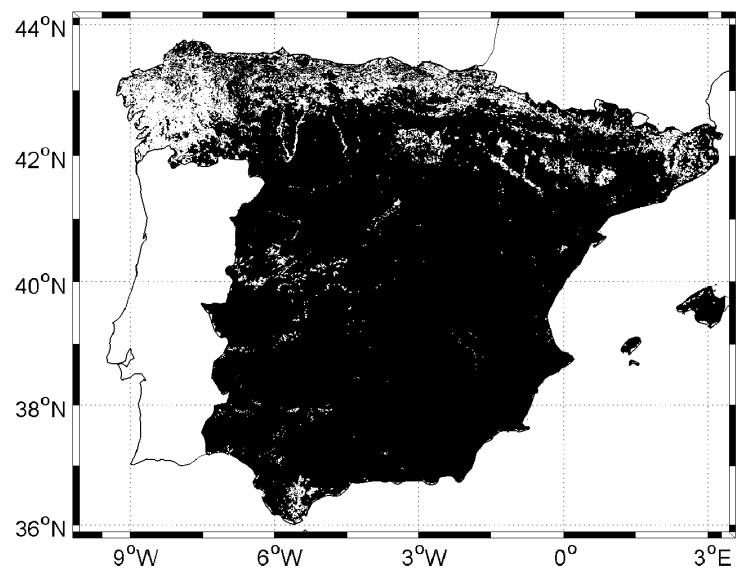

Figure 5. The model underestimates the annual GPP in the lighter peixls when using NDVI.

The consideration of different vegetation types implies adjusting the distributions in Figure $4 \mathrm{a}, \mathrm{b}$ using different regression lines. The hybrid land-cover map for the study area [44] has been used to apply the cross-validation procedure for each vegetation class: (1) irrigated lands; (2) cultivated areas; (3) cropland mosaic; (4) broad-leaved forest; (5) needle-leaved forest; (6) mixed forest; (7) shrubs; (8) herbaceous; and (9) sparse vegetation. As a result, values of $C_{1}$ and $C_{2}$ have been obtained for each 
iteration and for each land-cover type. For the sake of brevity, Tables 4 and 5 summarize the mean value and standard deviation of $C_{1}$ and $C_{2}$ for each land-cover type, as well as the global validation statistics. The correlation between the estimates and the reference annual GPP using the coefficients in Table 4 is shown in Figure 4e,f for NDVI and EVI, respectively. In Figure 4e, the cluster corresponding to highest GPP pixels distributes also along the 1:1 line and, thus, the global correlation between NDVI estimated and reference annual GPP data increases from 0.87 to 0.90 (last column in Table 5) when considering different values of $C_{1}$ and $C_{2}$ for each land-cover type. However, when using the EVI the estimates hardly improve. Therefore, with EVI the uncertainties of the estimates are rather good even without using a vegetation map.

Table 4. Mean value and standard deviation (below each value, between brackets) of the regression coefficients for each land-cover type. Code: (1) irrigated lands; (2) cultivated areas; (3) cropland mosaic; (4) broad-leaved forest; (5) needle-leaved forest; (6) mixed forest; (7) shrubs; (8) herbaceous; and (9) sparse vegetation. $C_{1}$ and $C_{2}$ are expressed in $\mathrm{kg} \cdot \mathrm{m}^{-2} \cdot \mathrm{yr}^{-1}$. Results are shown for NDVI and EVI.

\begin{tabular}{|c|c|c|c|c|c|c|c|c|c|}
\hline \multicolumn{10}{|c|}{ NDVI } \\
\hline & 1 & 2 & 3 & 4 & 5 & 6 & 7 & 8 & 9 \\
\hline$C_{1}$ & $\begin{array}{l}-1.610 \\
(0.009)\end{array}$ & $\begin{array}{l}-1.143 \\
(0.007)\end{array}$ & $\begin{array}{l}-1.190 \\
(0.017)\end{array}$ & $\begin{array}{l}-1.50 \\
(0.03)\end{array}$ & $\begin{array}{l}-1.046 \\
(0.011)\end{array}$ & $\begin{array}{l}-1.44 \\
(0.02)\end{array}$ & $\begin{array}{l}-0.975 \\
(0.009)\end{array}$ & $\begin{array}{l}-1.194 \\
(0.013)\end{array}$ & $\begin{array}{l}-1.019 \\
(0.008)\end{array}$ \\
\hline$C_{2}$ & $\begin{array}{c}5.682 \\
(0.018)\end{array}$ & $\begin{array}{c}4.164 \\
(0.018)\end{array}$ & $\begin{array}{c}4.20 \\
(0.03)\end{array}$ & $\begin{array}{c}4.68 \\
(0.04)\end{array}$ & $\begin{array}{c}3.561 \\
(0.019)\end{array}$ & $\begin{array}{c}4.40 \\
(0.04)\end{array}$ & $\begin{array}{c}3.302 \\
(0.017)\end{array}$ & $\begin{array}{c}4.15 \\
(0.02)\end{array}$ & $\begin{array}{c}3.62 \\
(0.02)\end{array}$ \\
\hline \multicolumn{10}{|c|}{ EVI } \\
\hline & 1 & 2 & 3 & 4 & 5 & 6 & 7 & 8 & 9 \\
\hline$C_{1}$ & $\begin{array}{c}-1.825 \\
(0.011)\end{array}$ & $\begin{array}{c}-1.562 \\
(0.007)\end{array}$ & $\begin{array}{l}-1.311 \\
(0.018)\end{array}$ & $\begin{array}{l}-1.15 \\
(0.02)\end{array}$ & $\begin{array}{c}-1.498 \\
(0.009)\end{array}$ & $\begin{array}{l}-1.01 \\
(0.02)\end{array}$ & $\begin{array}{l}-1.421 \\
(0.007)\end{array}$ & $\begin{array}{l}-1.337 \\
(0.013)\end{array}$ & $\begin{array}{c}-1.735 \\
(0.007)\end{array}$ \\
\hline$C_{2}$ & $\begin{array}{c}7.99 \\
(0.03)\end{array}$ & $\begin{array}{c}6.68 \\
(0.02)\end{array}$ & $\begin{array}{c}6.25 \\
(0.04)\end{array}$ & $\begin{array}{c}6.15 \\
(0.05)\end{array}$ & $\begin{array}{c}6.95 \\
(0.03)\end{array}$ & $\begin{array}{c}5.77 \\
(0.06)\end{array}$ & $\begin{array}{c}6.319 \\
(0.017)\end{array}$ & $\begin{array}{c}6.25 \\
(0.03)\end{array}$ & $\begin{array}{c}7.29 \\
(0.03)\end{array}$ \\
\hline
\end{tabular}

The different vegetation types present rather similar statistics. Cultivated areas, croplands and herbaceous show high coefficient of correlation values, and irrigated lands and shrubs show the lowest values, though still relatively high. The lower rMBE values correspond to herbaceous and needle-leaved forest. When analyzing the spatial dependence of the estimates uncertainties (average for all the years), for example in terms of the rMBE, it is observed that most of the estimates present a bias around zero (Figure 6), and the different vegetation types present rather similar values. When using constant regressions coefficients, for the estimates from both NDVI (Figure 6a) and EVI (Figure 6b), $20 \%$ of the pixels have $|\mathrm{rMBE}| \leq 5 \%$ (and $68 \%$ of the pixels have $|\mathrm{rMBE}| \leq 20 \%$ ). When using coefficients depending on the vegetation type, the $24 \%$ of pixels have $|\mathrm{rMBE}| \leq 5 \%$ (and $73 \%$ have $|\mathrm{rMBE}| \leq 20 \%$ ) for NDVI (Figure $6 \mathrm{c}$ ) and EVI (Figure 6d). The rMBE image using both constant and vegetation-type dependent values of $C_{1}$ and $C_{2}$, shows that in the second case the red and blue areas (overestimation and underestimation) are reduced (Figure 6). That is, when considering variable $C_{1}$ and $C_{2}$, the bias of the semi-empirical model is slightly reduced. However, when using NDVI some areas located in $\mathrm{W}$ (small area with very low vegetation cover) and SE Spain still present overestimates of ca. $100 \%$. Something similar occurs in the semiarid Ebro basin in NE Spain when using instead the EVI. Those areas located in SE and NW Spain comprise semiarid lands with a very low productivity (see Figure 1c). Then, although the bias is important in relative terms, it is not so in absolute terms because the aforementioned areas have very low GPP. Other areas presenting bias between $20 \%$ and $40 \%$ can also be identified, which are not clearly associated with a vegetation type. The presence of some areas with significant bias might be associated with the thematic map used. However, the use of an ecosystem functional type map [38] produces no improvement. The global statistics for the validation when using this alternative map with NDVI are $\mathrm{R}=0.88, \mathrm{rMBE}=-0.010, \mathrm{rMAE}=0.18$, and $\mathrm{rRMSE}=0.2$. That is, the correlation between the model estimates and the reference GPP is 
decreased, and the uncertainties are slightly increased, with respect to those obtained using the hybrid classification map.

Table 5. Validation statistics for each vegetation type and for the whole data set. Code: (1) irrigated lands; (2) cultivated areas; (3) cropland mosaic; (4) broad-leaved forest; (5) needle-leaved forest; (6) mixed forest; (7) shrubs; (8) herbaceous; and (9) sparse vegetation. MBE, MAE and RMSE are expressed in $\mathrm{kg} \cdot \mathrm{m}^{-2} \cdot \mathrm{yr}^{-1}$. Results are shown NDVI and EVI.

\begin{tabular}{ccccccccccc}
\hline \multicolumn{7}{c}{ NDVI } \\
\hline & $\mathbf{1}$ & $\mathbf{2}$ & $\mathbf{3}$ & $\mathbf{4}$ & $\mathbf{5}$ & $\mathbf{6}$ & $\mathbf{7}$ & $\mathbf{8}$ & $\mathbf{9}$ & Global \\
\hline $\mathbf{R}$ & 0.75 & 0.90 & 0.89 & 0.83 & 0.79 & 0.83 & 0.75 & 0.89 & 0.84 & 0.90 \\
MBE & 0.0011 & -0.005 & 0.007 & 0.006 & -0.002 & -0.0003 & -0.013 & -0.004 & -0.013 & -0.007 \\
MAE & 0.3 & 0.13 & 0.18 & 0.2 & 0.18 & 0.2 & 0.2 & 0.16 & 0.16 & 0.17 \\
RMSE & 0.4 & 0.18 & 0.2 & 0.3 & 0.2 & 0.3 & 0.3 & 0.2 & 0.2 & 0.2 \\
rMBE & 0.0008 & -0.007 & 0.005 & 0.004 & -0.0017 & -0.00018 & -0.015 & -0.004 & -0.018 & -0.007 \\
rMAE & 0.2 & 0.16 & 0.13 & 0.15 & 0.15 & 0.12 & 0.2 & 0.15 & 0.2 & 0.16 \\
rRMSE & 0.3 & 0.2 & 0.18 & 0.19 & 0.2 & 0.16 & 0.3 & 0.2 & 0.3 & 0.2 \\
\hline & & & & & $\mathbf{E V I}$ & & & & & \\
\hline & $\mathbf{1}$ & $\mathbf{2}$ & $\mathbf{3}$ & $\mathbf{4}$ & $\mathbf{5}$ & $\mathbf{6}$ & $\mathbf{7}$ & $\mathbf{8}$ & $\mathbf{9}$ & $\mathbf{G l o b a l}$ \\
\hline R & 0.76 & 0.90 & 0.90 & 0.84 & 0.81 & 0.85 & 0.80 & 0.90 & 0.87 & 0.91 \\
MBE & 0.005 & -0.009 & 0.0005 & 0.002 & 0.004 & -0.0019 & -0.007 & -0.006 & -0.008 & -0.009 \\
MAE & 0.3 & 0.13 & 0.18 & 0.2 & 0.17 & 0.18 & 0.19 & 0.16 & 0.14 & 0.16 \\
RMSE & 0.4 & 0.18 & 0.2 & 0.3 & 0.2 & 0.2 & 0.2 & 0.2 & 0.19 & 0.2 \\
rMBE & 0.004 & -0.011 & 0.0004 & 0.0015 & 0.004 & -0.0012 & -0.008 & -0.005 & -0.011 & -0.009 \\
rMAE & 0.2 & 0.16 & 0.13 & 0.14 & 0.14 & 0.11 & 0.2 & 0.15 & 0.19 & 0.16 \\
rRMSE & 0.3 & 0.2 & 0.18 & 0.18 & 0.19 & 0.15 & 0.3 & 0.19 & 0.3 & 0.2 \\
\hline
\end{tabular}

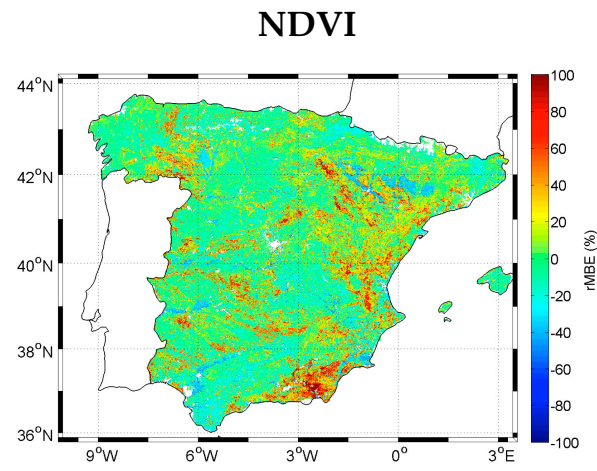

(a)

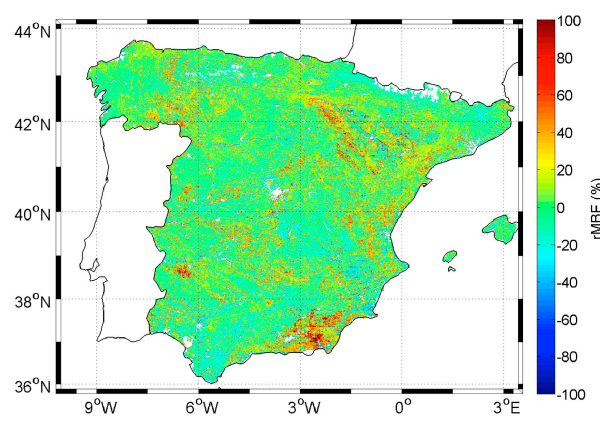

(c)
EVI

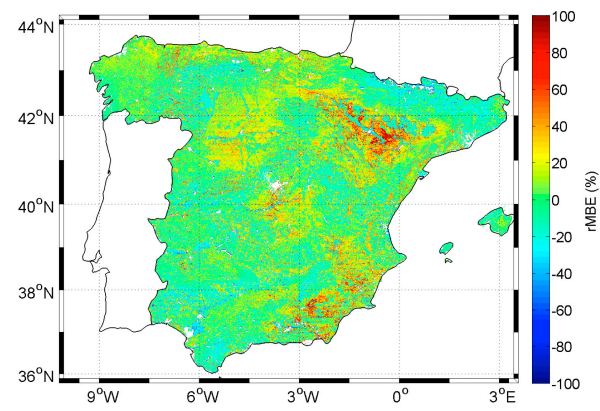

(b)

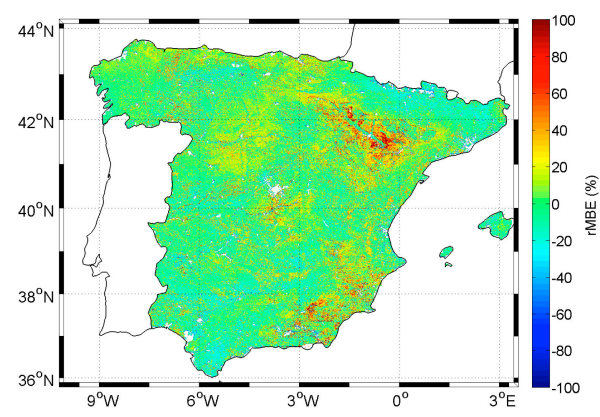

(d)

Figure 6. Mean rMBE (\%) image showing the spatial distribution of the discrepancies between the estimated and the reference annual GPP: (a) Estimated annual GPP using the semi-empirical model with NDVI and with constant values of $C_{1}$ and $C_{2}$; and (c) considering $C_{1}$ and $C_{2}$ as a function of the land-cover type; (b) Estimated annual GPP using the semi-empirical model with EVI and with constant values of $C_{1}$ and $C_{2}$; and (d) considering $C_{1}$ and $C_{2}$ as a function of the land-cover type (red colors correspond to overestimates and blue color to underestimates). 
As mentioned above, Figure 6 shows average uncertainties for all the years when using the hybrid classification map. For the year 2011, the comparison between reference and estimated annual GPP data (Figure 7) shows a similar spatial pattern, although the model slightly underestimates GPP in highly productive areas corresponding to dense forests (Figure 5), more noticeable when using NDVI.

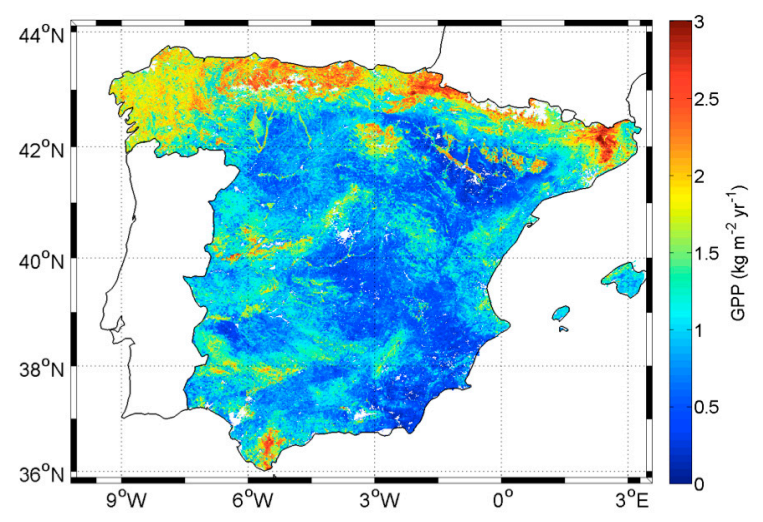

(a)

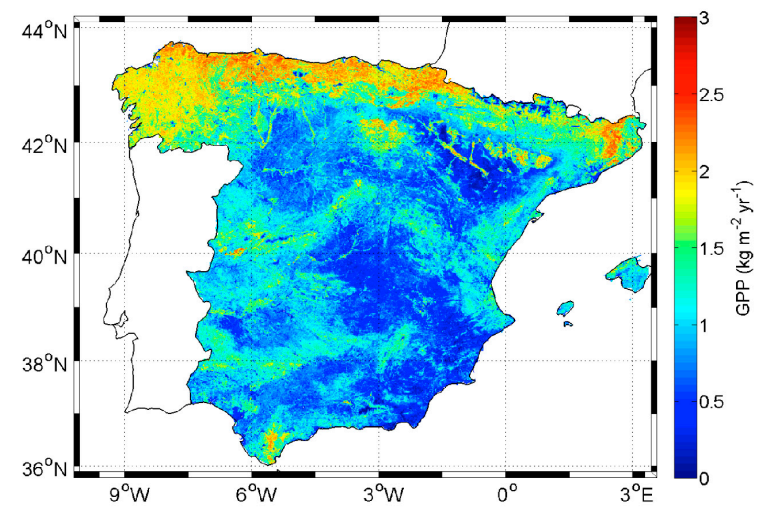

(b)

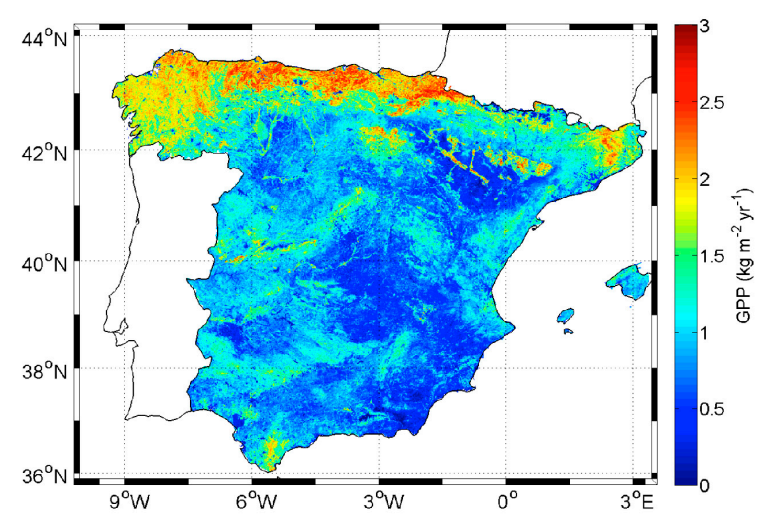

(c)

Figure 7. (a) Reference annual GPP and estimated GPP annual (in $\mathrm{kg} \cdot \mathrm{m}^{-2} \cdot \mathrm{yr}^{-1}$ ) for 2011 using: (b) NDVI; and (c) EVI.

Finally, as an example, Figure 8 shows the annual GPP images for the 2005-2012 period obtained using the proposed model with EVI and the coefficients in Table 4 . The observed inter-annual variability in GPP is influenced mostly by changes in structural parameters of the vegetation, and thus by the EVI, which is connected with precipitation pattern. When precipitation diminishes, for example in 2005 [47], a reduction in GPP is observed. In a wetter year, such as 2010, an increase of GPP is shown. 


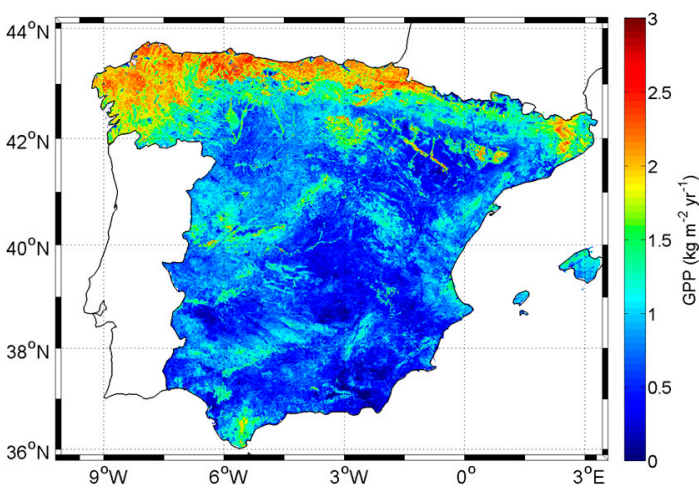

(a) 2005

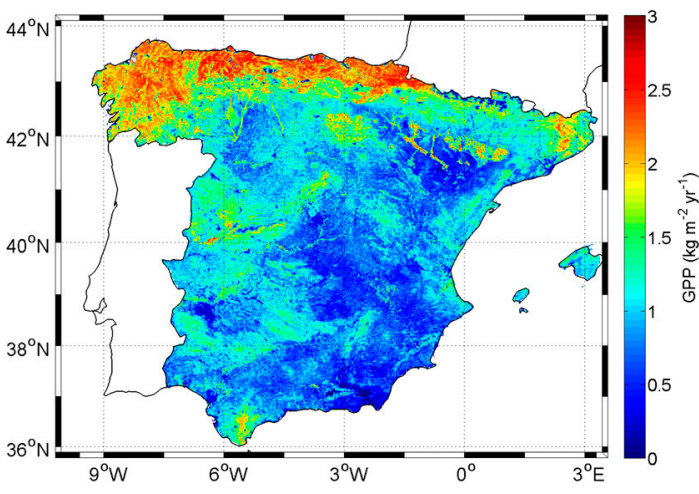

(c) 2007

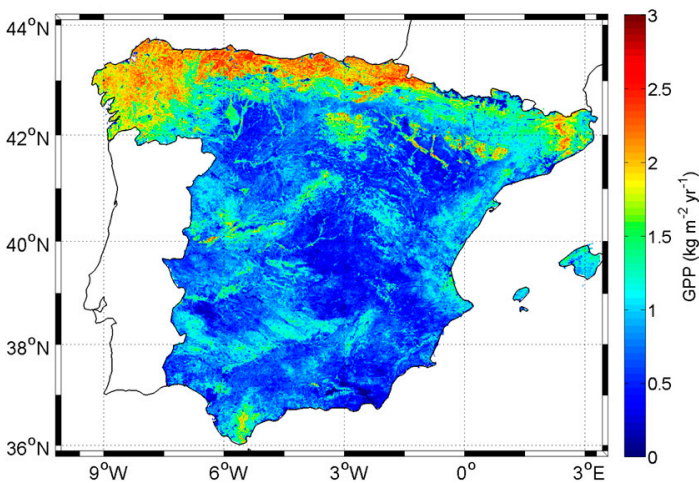

(e) 2009

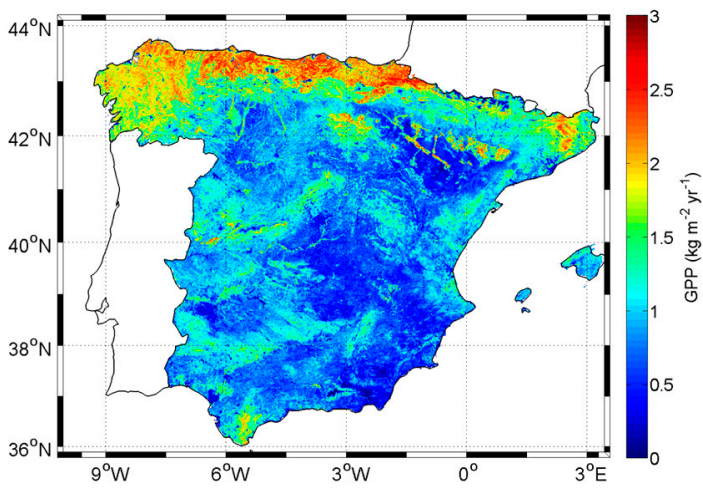

(g) 2011

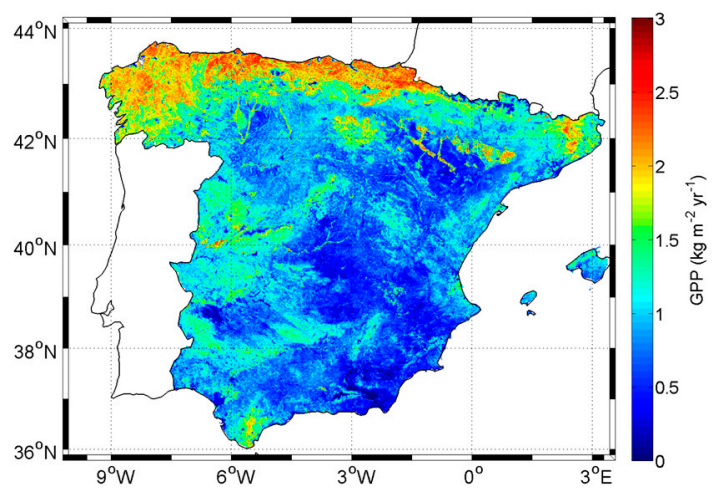

(b) 2006

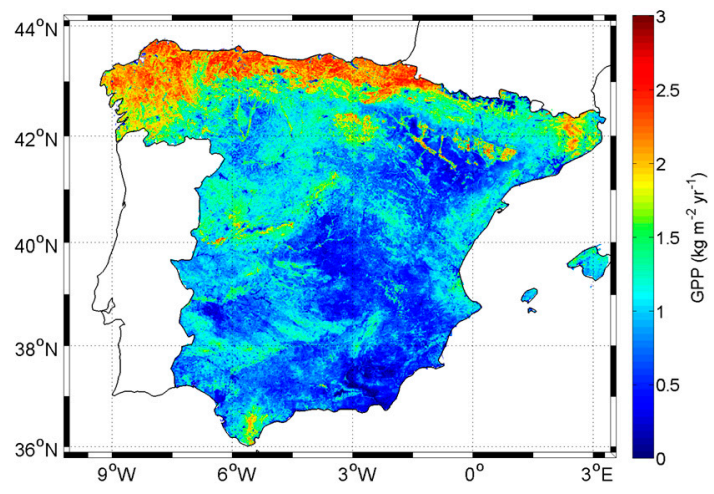

(d) 2008

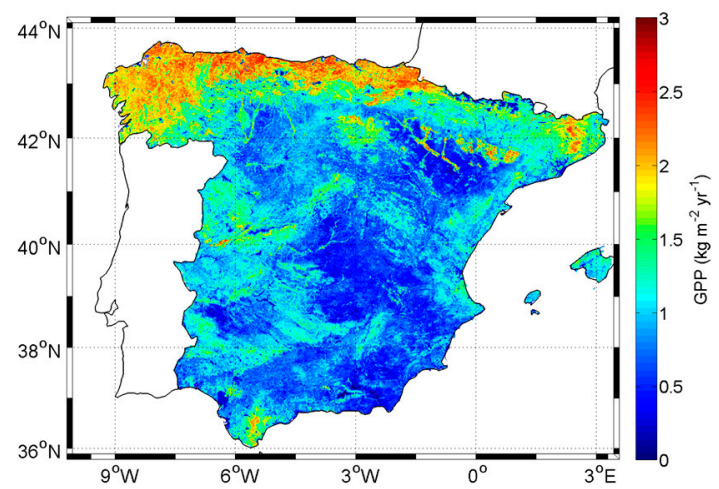

(f) 2010

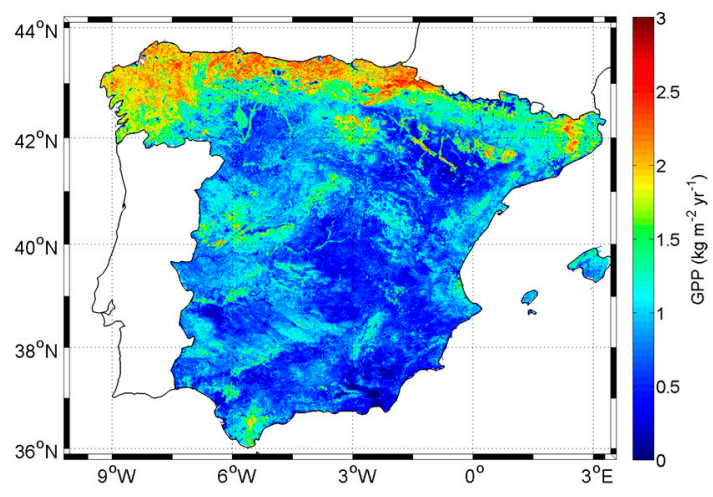

(h) 2012

Figure 8. Images of $\mathrm{GPP}_{\text {annual }}$ (in $\mathrm{kg} \cdot \mathrm{m}^{-2} \cdot \mathrm{yr}^{-1}$ ) for the 2005-2012 period obtained using the semi-empirical model with EVI and the coefficients in Table 4. 


\section{Discussion}

The proposed semi-empirical model to estimate GPP does not require actual meteorological data. It exclusively relies on a vegetation index product commonly available-the MOD13A2 in this case-and on a representative PAR.

The underlying assumption of the model is that VI is the main factor determining the GPP inter-annual variations. The use of a representative PAR in our model marks a qualitative distinction from those approaches based on a linear relationship between an annual cumulative or mean VI and the annual GPP $[2,48,49]$. The rationale of our model is also different from the greenness-radiation models that consider GPP equal to the product of a VI and PAR [50]. Certainly, a key factor accounting for the annual GPP is the annual cumulative or mean VI, but our model calculates a PAR-weighted annual mean VI. The use of the representative daily PAR as a weighting factor is important because VI gives the fraction of PAR absorbed but not the total absolute PAR absorbed. The same VI can produce different GPP depending on the incident radiation, and the latter shows a marked seasonal variability that affects differently the different vegetation types, depending on their phenology.

The calibration/validation process, however, does require a reference GPP product and, obviously, the higher the quality of the reference GPP product, the better the performance of the semi-empirical model. In this study, a daily GPP product optimized for the study area has been used to calculate the reference annual GPP instead of using the annual GPP from MODIS (MOD17A3). Although both products show a temporal consistency [4], our product benefits from: an accurate PAR product, a land-cover map more adapted to the study area and a water stress factor that better accounts for the photosynthesis reduction during the summer water shortage. Nevertheless, the MOD17A3 product can be also used as reference to calibrate the model (and could even be recommended for a global study). In order to further test the methodology robustness, the calibration/validation process has been repeated using MOD17A3 as reference for both VIs and considering both constant regression coefficients and coefficients depending on the vegetation type (Table 6).

Table 6. Summary of the validation statistics (R, rRMSE, rMBE and rMAE) of the semi-empirical model estimates when driven by NDVI and EVI (with and without a vegetation map) and using as reference $\mathrm{GPP}_{\mathrm{annual}}^{\mathrm{REF}}$ the aforementioned GPP product optimized for the study area $\left(\mathrm{GPP}_{\mathrm{OPT}}\right)$ as well as the official MODIS GPP product MOD17A3 (GPP MODIS).

\begin{tabular}{|c|c|c|c|c|}
\hline & \multicolumn{2}{|r|}{ NDVI } & \multicolumn{2}{|r|}{ EVI } \\
\hline & $\begin{array}{l}\text { Constant Values } \\
\text { of } C_{1} \text { and } C_{2}\end{array}$ & $\begin{array}{c}C_{1} \text { and } C_{2} \text { Values } \\
\text { Depending on Vegetation }\end{array}$ & $\begin{array}{l}\text { Constant Values } \\
\text { of } C_{1} \text { and } C_{2}\end{array}$ & $\begin{array}{c}C_{1} \text { and } C_{2} \text { Values } \\
\text { Depending on Vegetation }\end{array}$ \\
\hline $\begin{array}{l}\text { REFERENCE: } \\
\text { GPP }_{\text {OPT }}\end{array}$ & $\begin{array}{c}\mathrm{R}=0.87 \\
\mathrm{rRMSE}=0.3 \\
\mathrm{rMBE}=-0.008 \\
\mathrm{rMAE}=0.19\end{array}$ & $\begin{array}{c}\mathrm{R}=0.90 \\
\mathrm{rRMSE}=0.2 \\
\mathrm{rMBE}=-0.007 \\
\mathrm{rMAE}=0.16\end{array}$ & $\begin{array}{c}\mathrm{R}=0.90 \\
\mathrm{rRMSE}=0.2 \\
\mathrm{rMBE}=-0.009 \\
\mathrm{rMAE}=0.17\end{array}$ & $\begin{array}{c}\mathrm{R}=0.91 \\
\mathrm{rRMSE}=0.2 \\
\mathrm{rMBE}=-0.009 \\
\mathrm{rMAE}=0.16\end{array}$ \\
\hline $\begin{array}{l}\text { REFERENCE: } \\
\text { GPP }_{\text {MODIS }}\end{array}$ & $\begin{array}{c}\mathrm{R}=0.87 \\
\mathrm{rRMSE}=0.3 \\
\mathrm{rMBE}=-0.07 \\
\mathrm{rMAE}=0.17\end{array}$ & $\begin{array}{c}\mathrm{R}=0.87 \\
\mathrm{rRMSE}=0.3 \\
\mathrm{rMBE}=-0.05 \\
\mathrm{rMAE}=0.16\end{array}$ & $\begin{array}{c}\mathrm{R}=0.84 \\
\mathrm{rRMSE}=0.3 \\
\mathrm{rMBE}=-0.07 \\
\mathrm{rMAE}=0.2\end{array}$ & $\begin{array}{c}\mathrm{R}=0.86 \\
\mathrm{rRMSE}=0.3 \\
\mathrm{rMBE}=-0.05 \\
\mathrm{rMAE}=0.18\end{array}$ \\
\hline
\end{tabular}

Table 6 confirms that the MOD17A3 product can be also used as reference to calibrate the model, which significantly extends the range of applicability of the methodology. The additional requisite is the availability of a representative PAR image that could be estimated at the cost of a coarser spatial resolution from databases such as GMAO (Global Modeling Assimilation Office) or ECMWF (European Center for Medium-Range Weather Forecast).

Since the results have shown a good agreement with reference data, the proposed methodology can be used to generate long series of annual GPP to detect regional changes without requiring actual PAR, $f_{\text {APAR }}$ and $\varepsilon$. As commented in the literature [27], the absorbed photosynthetic radiation and $\varepsilon$ are somehow linked; in this work, the link is established by means of the vegetation indices NDVI 
and EVI. The time series of EVI is shorter than the NDVI one and it is limited to sensors with the blue band. Nevertheless, a longer series could be generated using the two-band enhanced vegetation index, EVI2 [51], which is an acceptable and accurate substitute of EVI without the blue band.

Annual GPP could be obtained even when no classification map is available with similar uncertainty when using EVI (and with a slightly higher uncertainty in the case of using NDVI), or even in global studies using lower spatial resolution images such as SEVIRI-MSG. On the other hand, there is no need to work with daily images. It is possible to work directly with the original MODIS products, for example, the NDVI at 16-day temporal resolution, or even with a monthly NDVI without losing functionality. To assess their performance, the annual GPP has been calculated using both products with constant $C_{1}$ and $C_{2}$. The validation statistics using the 16-day and 30-day products are exactly the same as those from the daily product shown in Table 3. Only a negligible change in the bias (from -0.008 to -0.007 ) is observed when using monthly NDVI values.

The model, mainly when it is driven with NDVI, overestimates the annual GPP in semiarid areas and slightly underestimates it in dense forest areas. This conclusion has been reached when using both a vegetation class map and an ecosystem functional type map. The overestimation in semiarid areas when using NDVI might be a consequence of NDVI sensitivity to canopy background variations, especially important in sparse vegetation areas (as bare soil NDVI does not equal to zero, then $f_{\text {APAR }}$ is slightly overestimated). This overestimation, although reduced, is not completely removed when using EVI. A light, general, GPP overestimation is found in semiarid areas. It could be a consequence of the photosynthesis reduction due to water stress that is not completely taken into account by the semi-empirical model, which evidences that the hypothesis H3 might be somehow inaccurate, that is, the vegetation index decrease does not fully characterize the photosynthesis reduction by water stress. However, the GPP in these areas is very low and therefore the absolute value of the uncertainty is low.

On the other hand, the underestimation in dense forest areas could be attributed to the NDVI saturation at high LAI levels. Generally, most vegetation indices approach a saturation level asymptotically in high biomass regions and for a certain range of LAI values [8]. The dynamic range and the saturation depend on the particular VI. We found the NDVI to asymptotically saturate in dense forest areas while the EVI remained sensitive to canopy variations (Figure $4 \mathrm{~b}$ ). Thus the model benefits from the wider dynamic range of EVI, slightly improving the GPP estimation over dense forests as previously shown in closed forest stands (for example in Sweden [52]). Despite this improvement, a very light, general underestimation of GPP in dense forest areas is still observed and it might be attributed to the fact that the leaf photosynthetic response to light is a non-linear process. Although the integration over time scales of two weeks or more tends to linearize the photosynthesis response curve to light [15], it seems that the non-linearity has not been completely removed. Boreal forest, much denser than Mediterranean forest, would be potentially more affected by this effect and thus no conclusions can be derived on the performing of our model in these areas.

\section{Conclusions}

The annual GPP has been estimated at 1-km spatial resolution from the MODIS standard VI products (NDVI and EVI) and the semi-empirical model, Equation (4), with $C_{1}$ and $C_{2}$ obtained, as a function of the vegetation type, as the coefficients of the linear regression between the reference annual GPP — calculated using Equation (2) with daily GPP data [4] - and the PAR-weighted average VI (Equation (7)).

The main advantage of the semi-empirical model to estimate annual GPP is that it does not require actual meteorological data, thus solving a problem that is often faced, especially in retrospective studies. The model exclusively relies on a vegetation index product commonly available - the MOD13A2 in this case-and on a representative PAR (calculated for a time period sufficiently long although that might not be the same as the period when GPP is estimated). The calibration/validation process, however, does require a reference GPP product and, obviously, the higher the quality of the reference GPP product, the better the performance of the semi-empirical model. 
The performance of the model has been assessed in its ability to reproduce inter-annual variations of GPP in close agreement with those shown by the reference data. A total of eight essays have been performed using all the possible combination among the model driven by: NDVI or EVI, with or without vegetation map, and using as reference a previous GPP product generated by the authors [4] or the MODIS GPP product. The different statistics (Table 6) have shown a good agreement between the estimates and the reference data sets, with correlation coefficient between 0.84 and 0.91 and relative RMSE between $20 \%$ and $30 \%$ in all the cases, enhancing the robustness of the method and its applicability to other regions and potentially to other sensors with similar o lower spatial and temporal resolutions. However, special attention must be given to its applicability in semiarid areas, where the semi-empirical model overestimates the annual GPP, and in very dense forest areas, where the model slightly underestimates GPP. In the latter case, uncertainties are lower when using EVI instead of NDVI. Besides improving vegetation monitoring over high biomass conditions, EVI offers some other advantage: its performance does not depend on a vegetation map and hence this map is not a crucial requirement to apply the methodology.

With the above limitations, it is concluded that the proposed semi-empirical model provides an excellent compromise between simplicity and accuracy for the calculation of long time series of annual GPP.

Acknowledgments: This work has been partially supported by ESCENARIOS (MINECO, CGL2016-75239-R), RESET CLIMATE (MINECO, CGL2012-35831) and LSA SAF (EUMETSAT) projects. Special thanks are due to José A. Manzanares for their valuable suggestions. The MOD13A2 and MOD17A3 products were retrieved from the online Reverb, courtesy of the NASA EOSDIS Land Processes Distributed Active Archive Center (LP DAAC), USGS/Earth Resources Observation and Science (EROS) Center, Sioux Falls, South Dakota (reverb.echo.nasa.gov). The authors would like to thank the anonymous reviewers for their valuable comments.

Author Contributions: All authors contributed equally to the development of this research.

Conflicts of Interest: The authors declare no conflict of interest.

\section{References}

1. Reichtein, M.; Falge, E.; Baldocchi, D.; Papale, D.; Aubinet, M.; Berbigier, P.; Bernhofer, C.; Buchmann, N.; Gilmanov, T.; Granier, A.; et al. On the separation of net ecosystem exchange into assimilation and ecosystem respiration: Review and improved algorithm. Glob. Chang. Ecol. 2005, 11, 1424-1439. [CrossRef]

2. Huete, A.; Ponce-Campos, G.; Zhang, Y.; Restrepo-Coupe, N.; Ma, X.; Moran, M.S. Monitoring photosynthesis from space. In Land Resources Monitoring, Modeling, and Mapping with Remote Sensing; Thenkabail, P.S., Ed.; CRC Press: Boca Raton, FL, USA, 2015; pp. 3-22.

3. Mäkelä, A.; Kolari, P.; Karimäki, J.; Nikinmaa, E.; Perämäki, M.; Hari, P. Modelling five years of weather-driven variation of GPP in a boreal forest. Agric. For. Meteorol. 2006, 139, 382-398. [CrossRef]

4. Gilabert, M.A.; Moreno, A.; Maselli, F.; Martínez, B.; Chiesi, M.; Sánchez-Ruiz, S.; García-Haro, F.J.; Pérez-Hoyos, A.; Campos-Taberner, M.; Pérez-Priego, O.; et al. Daily GPP estimates in Mediterranean ecosystems by combining remote sensing and meteorological data. ISPRS J. Photogramm. Remote Sens. 2015, 102, 184-197. [CrossRef]

5. Maselli, F.; Papale, D.; Puletti, N.; Chirici, G.; Corona, P. Combining remote sensing and ancillary data to monitor the gross productivity of water-limited forest ecosystems. Remote Sens. Environ. 2009, 113, 657-667.

6. Monteith, J.L. Solar radiation and productivity in tropical ecosystems. J. Appl. Ecol. 1972, 9, 747-766. [CrossRef]

7. Rouse, J.W.; Haas, R.H.; Schell, J.A.; Deering, D.W.; Harlan, J.C. Monitoring the Vernal Advancements and Retrogradation of Natural Vegetation; Final Report; NASA Goddard Space Flight Center: Greenbelt, MD, USA, 1974; pp. 1-137.

8. Huete, A.; Didan, K.; Miura, T.; Rodriguez, E.P.; Gao, X.; Ferreira, L.G. Overview of the radiometric and biophysical performance of the MODIS vegetation indices. Remote Sens. Environ. 2002, 83, 195-213. [CrossRef]

9. Lean, J.L. Cycles and trends in solar irradiance and climate. WIREs Clim. Chang. 2010, 1, 111-122. [CrossRef] 
10. Stanhill, G.; Cohen, S. Global dimming: A review of the evidence for a widespread and significant reduction in global radiation with discussion of its probable causes and possible agricultural consequences. Agric. For. Meteorol. 2001, 107, 255-278. [CrossRef]

11. Wild, M.; Gilgen, H.; Roesch, A.; Ohmura, A.; Long, C.N.; Dutton, E.G.; Forgan, B.; Kallis, A.; Russak, V.; Tsvetkov, A. From dimming to brightening: Decadal changes in solar radiation at Earth's surface. Science 2005, 308, 845-850. [CrossRef] [PubMed]

12. Black, K.; Davis, P.; Lynch, P.; Jones, M.; McGettigan, M.; Osborne, B. Long-term trends in solar irradiance in Ireland and their potential effects on gross primary productivity. Agric. For. Meteorol. 2006, 141, 118-132. [CrossRef]

13. Jongen, M.; Pereira, J.S.; Aires, L.M.I.; Pio, C.A. The effects of drought and timing of precipitation on the inter-annual variation in ecosystem-atmosphere exchange in a Mediterranean grassland. Agric. For. Meteorol. 2011, 151, 595-606. [CrossRef]

14. Higuchi, K.; Shashkov, A.; Chan, D.; Saigusa, N.; Murayama, S.; Yamamoto, S.; Kondo, H.; Chen, J.; Liu, J.; Chen, B. Simulations of seasonal and inter-annual variability of gross primary productivity at Takayama with BEPS ecosystem model. Agric. For. Meteorol. 2005, 134, 143-150. [CrossRef]

15. Medlyn, B.; Barrett, D.; Landsberg, J.; Sands, J.; Sands, P.; Clement, R. Conversion of canopy intercepted radiation to photosynthate: Review of modelling approaches for regional scales. Funct. Plant Biol. 2003, 30, 153-169. [CrossRef]

16. Fensholt, R.; Sandholt, I.; Rasmussen, M.S. Evaluation of MODIS LAI, fAPAR and the relation between fAPAR and NDVI in a semi-arid environment using in situ measurements. Remote Sens. Environ. 2004, 91, 490-507. [CrossRef]

17. Huemmrich, K.F.; Gamon, J.A.; Tweedie, C.E.; Oberbauer, S.F.; Kinoshita, G.; Houston, S.; Kuchy, A.; Hollister, R.D.; Kwon, H.; Mano, M.; et al. Remote sensing of tundra gross ecosystem productivity and light use efficiency under varying temperature and moisture conditions. Remote Sens. Environ. 2010, 114, 481-489. [CrossRef]

18. Sims, D.A.; Rahman, A.F.; Cordova, V.D.; El-Masri, B.Z.; Baldocchi, D.D.; Flanagan, L.B.; Goldstein, A.H.; Hollinger, D.Y.; Misson, L.; Monson, R.K.; et al. On the use of MODIS EVI to assess gross primary productivity of North American ecosystems. J. Geophys. Res. 2006. [CrossRef]

19. Viña, A.; Gitelson, A.A. New developments in the remote estimation of the fraction of absorbed photosynthetically active radiation in crops. Geophys. Res. Lett. 2005. [CrossRef]

20. Wu, C.; Chen, J.M.; Desai, A.R.; Hollinger, D.Y.; Arain, M.A.; Margolis, H.A.; Gough, C.M.; Staebler, R.M. Remote sensing of canopy light use efficiency in temperate and boreal forests of North America using MODIS imagery. Remote Sens. Environ. 2012, 118, 60-72. [CrossRef]

21. Wu, C.; Niu, Z.; Gao, S. Gross primary production estimation from MODIS data with vegetation index and photosynthetically active radiation in maize. J. Geophys. Res. 2010. [CrossRef]

22. Dong, J.; Xiao, X.; Wagle, P.; Zhang, G.; Zhou, Y.; Jin, C.; Torno, M.S.; Meyers, T.P.; Suyker, A.E.; Wang, J.; et al. Comparison of four EVI-based models for estimating gross primary production of maize and soybean croplands and tallgrass prairie under severe drought. Remote Sens. Environ. 2015, 162, 154-168. [CrossRef]

23. Gamon, J.A.; Peñuelas, J.; Field, C.B. A narrow-waveband spectral index that tracks diurnal changes in photosynthetic efficiency. Remote Sens. Environ. 1992, 41, 35-44. [CrossRef]

24. Soudani, K.; Hmimina, G.; Dufrene, E.; Berbeiller, D.; Delpierre, N.; Ourcival, J.-M.; Rambal, S.; Joffre, R. Relationships between photochemical reflectance index and light-use efficiency in deciduous and evergreen broadleaf forests. Remote Sens. Environ. 2014, 144, 73-84. [CrossRef]

25. Gitelson, A.; Peng, Y.; Arkebauer, T.J.; Schepers, J. Relationships between gross primary production, green LAI, and canopy chlorophyll content in maize: Implications for remote sensing of primary production. Remote Sens. Environ. 2014, 144, 65-72. [CrossRef]

26. Gitelson, A.A.; Viña, A.; Verma, S.B.; Rundquist, D.C.; Arkebauer, T.J.; Keydan, G.; Leavitt, B.; Ciganda, V.; Burba, G.G.; Suyker, A.E. Relationship between gross primary production and chlorophyll content in crops: Implications for the synoptic monitoring of vegetation productivity. Geophys. Res. Lett. 2006. [CrossRef]

27. Gitelson, A.; Gamon, J.A. The need for a common basis for defining light-use efficiency: Implications for productivity estimation. Remote Sens. Environ. 2015, 156, 196-201. [CrossRef] 
28. Connolly, J.; Roulet, N.T.; Seaquist, J.W.; Holden, N.M.; Lafleur, P.M.; Humphreys, E.R.; Heumann, B.W.; Ward, S.M. Using MODIS derived fPAR with ground based flux tower measurements to derive the light use efficiency for two Canadian peatlands. Biogeosciences 2009, 6, 225-234. [CrossRef]

29. Coops, N.C.; Hilker, T.; Hall, F.G.; Nichol, C.J.; Drolet, G.G. Estimation of light-use efficiency of terrestrial ecosystems from space: A status report. BioScience 2010, 60, 788-797. [CrossRef]

30. Garbulsky, M.F.; Peñuelas, J.; Papale, D.; Ardö, J.; Goulden, M.L.; Kiely, G.; Richardson, A.D.; Rotenberg, E.; Veenendaal, E.M.; Filella, I. Patterns and controls of the variability of radiation use efficiency and primary productivity across terrestrial ecosystems. Glob. Ecol. Biogeogr. 2010, 19, 253-267. [CrossRef]

31. Kanniah, K.D.; Beringer, J.; Hutley, L.B. Response of savanna gross primary productivity to inter-annual variability in rainfall: Results of a remote sensing based light use efficiency model. Prog. Phys. Geogr. 2013, 37, 642-663. [CrossRef]

32. Turner, D.P.; Urbanski, S.; Bremer, D.; Wofsy, S.C.; Meyers, T.; Gower, S.T.; Gregory, M. A cross-biome comparison of daily light use efficiency for gross primary production. Glob. Chang. Biol. 2003, 9, 383-395. [CrossRef]

33. Moreno, A.; Maselli, F.; Gilabert, M.A.; Chiesi, M.; Martínez, B.; Seufert, G. Assessment of MODIS imagery to track light-use efficiency in a water-limited Mediterranean pine forest. Remote Sens. Environ. 2012, 123, 359-367. [CrossRef]

34. Moreno, A.; Maselli, F.; Chiesi, M.; Genesio, L.; Vaccari, F.; Seufert, G.; Gilabert, M.A. Monitoring water stress in Mediterranean semi-natural vegetation with satellite and meteorological data. Int. J. Appl. Earth Obs. Geoinf. 2014, 26, 246-255. [CrossRef]

35. Davenport, M.L.; Nicholson, S.E. On the relation between rainfall and the normalized difference vegetation index for diverse vegetation types in East Africa. Int. J. Remote Sens. 1993, 14, 2369-2389. [CrossRef]

36. Ichii, L.; Kawabata, A.; Yamaguchi, Y. Global correlation analysis for NDVI and climatic variables and NDVI trends: 1982-1990. Int. J. Remote Sens. 2002, 23, 3873-3878. [CrossRef]

37. Del Barrio, G.; Puigdefábregas, J.; Sanjuan, M.E.; Stellmes, M.; Ruiz, A. Assessment and monitoring of land condition in the Iberian Peninsula, 1989-2000. Remote Sens. Environ. 2010, 114, 1817-1832. [CrossRef]

38. Pérez-Hoyos, A.; Martínez, B.; García-Haro, F.J.; Moreno, A.; Gilabert, M.A. Identification of ecosystem functional types from coarse resolution imagery using a self-organizing map approach: A case study for Spain. Remote Sens. 2014, 6, 11391-11419. [CrossRef]

39. LSA SAF. Product User Manual “Down-Welling Surface Shotwave Flux (DSSF)", Version 2.6. 2011. Available online: http:/ /landsaf.meteo.pt/algorithms.jsp?seltab=1\&starttab=1 (accessed on 15 November 2016).

40. Moreno, A.; Gilabert, M.A.; Camacho, F.; Martínez, B. Validation of daily global solar irradiation images from MSG over Spain. Renew. Energy 2013, 60, 332-342. [CrossRef]

41. Moreno, A.; Gilabert, M.A.; Martínez, B. Mapping daily global solar irradiation over Spain: A comparative study of selected approaches. Sol. Energy 2011, 85, 2072-2084. [CrossRef]

42. Roujean, J.L.; Bréon, F.M. Estimating PAR absorbed by vegetation from bidirectional reflectance measurements. Remote Sens. Environ. 1995, 51, 373-384. [CrossRef]

43. Moreno, A.; García-Haro, F.J.; Martínez, B.; Gilabert, M.A. Noise reduction and gap filling of fAPAR series using an adapted local regression filter. Remote Sens. 2014, 6, 8238-8260. [CrossRef]

44. Pérez-Hoyos, A.; García-Haro, F.J.; San Miguel Ayanz, J. A methodology to generate a synergetic land-cover map by fusion of different land-cover products. Int. J. Appl. Earth Obs. Geoinf. 2012, 19, 72-87. [CrossRef]

45. Running, S.W.; Zhao, M. User's Guide: Daily GPP and Annual NPP (MOD17A2/A3) Products NASA Earth Observing System MODIS Land Algorithm, Version 3.0; University of Montana: Missoula, MT, USA, 2015; pp. 1-28.

46. Hastie, T.; Tibshirani, R.; Friedman, J. The Elements of Statistical Learning: Data Mining, Inference, and Prediction; Series in Statistics; Springer: New York, NY, USA, 2009; p. 763.

47. AEMet (Meteorological Agency, Spanish Government). Resumen Climatológico Annual 2005. Available online: http://www.aemet.es/documentos/es/serviciosclimaticos/vigilancia_clima/resumenes_ climat/anuales/res_anual_clim_2005.pdf (accessed on 23 July 2016).

48. Goward, S.N.; Tucker, C.; Dye, D. North American vegetation patterns observed with the NOAA-7 advanced very high resolution radiometer. Vegetatio 1985, 64, 3-14. [CrossRef]

49. Running, S.W.; Heinsch, F.A.; Zhao, M.; Reeves, M.; Hashimoto, H.; Nemani, R.R. A continuous satellite-derived measure of global terrestrial primary production. BioScience 2004, 54, 547-560. [CrossRef] 
50. Peng, Y.; Gitelson, A.A.; Sakamoto, T. Remote estimation of gross primary productivity in crops using MODIS 250 m data. Remote Sens. Environ. 2013, 128, 186-196. [CrossRef]

51. Jiang, Z.; Huete, A.R.; Didan, K.; Miura, T. Development of a two-band enhanced vegetation index without a blue band. Remote Sens. Environ. 2008, 112, 3833-3845. [CrossRef]

52. Shubert, P.; Eklundh, L.; Lund, M.; Nilsson, M. Estimating northern peatland $\mathrm{CO}_{2}$ exchange from MODIS time series data. Remote Sens. Environ. 2010, 114, 1178-1189. [CrossRef] 